SAND91-1526

Distribution

Unlimited Release

Printed November 1994

Category UC-403

\title{
BENCHMARK TESTING \\ AND INDEPENDENT VERIFICATION OF THE VS2DT COMPUTER CODE
}

\author{
James T. McCord \\ Environmental Risk Assessment and Risk Management Department \\ Sandia National Laboratories/New Mexico \\ Albuquerque, NM 87185-0727
}

Michael T. Goodrich

IT Corporation

5301 Central Avenue NE, Suite 700

Albuquerque, NM 87108

\begin{abstract}
The finite difference flow and transport simulator VS2DT was benchmark tested against several other codes which solve the same equaltions (Richards equation for flow and the AdvectionDispersion equation for transport). The benchmark problems investigated transient twodimensional flow in a heterogeneous soil profile with a localized water source at the ground surface. The VS2DT code performed as well as or better than all other codes when considering mass balance characterisitcs and computational speed. It was also rated highly relative to the other codes with regard to ease-of-use. Following the benchmark study, the code was verified against two analytical solutions, one for two-dimensional flow and one for two-dimensional transport. These independent verifications show reasonable agreement with the analytical solutions, and complement the one-dimensional verification problems published in the code's original documentation.
\end{abstract}


Intentionally Left Blank 


\section{DISCLAIMER}

This report was prepared as an account of work sponsored by an agency of the United States Government. Neither the United States Government nor any agency thereof, nor any of their employees, make any warranty, express or implied, or assumes any legal liability or responsibility for the accuracy, completeness, or usefulness of any information, apparatus, product, or process disclosed, or represents that its use would not infringe privately owned rights. Reference herein to any specific commercial product, process, or service by trade name, trademark, manufacturer, or otherwise does not necessarily constitute or imply its endorsement, recommendation, or favoring by the United States Government or any agency thereof. The views and opinions of authors expressed herein do not necessarily state or reflect those of the United States Government or any agency thereof. 


\section{DISCLAIMER}

Portions of this document may be illegible in electronic image products. Images are produced from the best available original document. 


\section{Contents}

List of Tables $\ldots \ldots \ldots \ldots \ldots \ldots \ldots \ldots \ldots \ldots \ldots$ iv

List of Figures $\ldots \ldots \ldots \ldots \ldots \ldots \ldots \ldots \ldots \ldots \ldots$

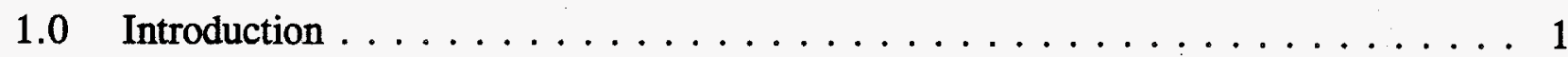

2.0 Mathematical Models $\ldots \ldots \ldots \ldots \ldots \ldots \ldots \ldots \ldots \ldots \ldots$

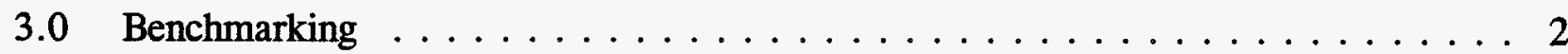

4.0 Benchmarking Results $\ldots \ldots \ldots \ldots \ldots \ldots \ldots \ldots \ldots \ldots$

4.1 Benchmark Problem 1-Infiltration Into Dry Soils . . . . . . . . . . 9

4.2 Benchmark Problem 2-Infiltration Into Very Dry Soils $\ldots \ldots \ldots \ldots$

4.3 Benchmark Problem 3-Steady Flow Problem . . . . . . . . . . . . 19

5.0 Qualitative Factors Comparison . . . . . . . . . . . . . . . 23

5.1 Code Documentation and Ease of Use $\ldots \ldots \ldots \ldots \ldots \ldots$

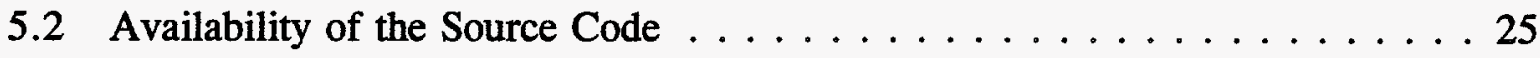

5.3 Level of Quality Assurance in Code Development . . . . . . . . . . 25

5.4 Additional Options and Capabilities . . . . . . . . . . . . 25

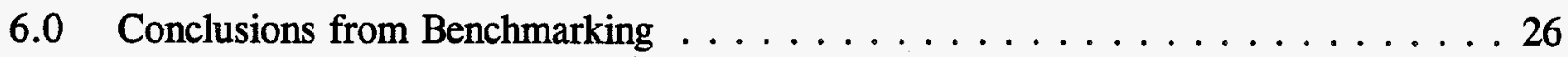

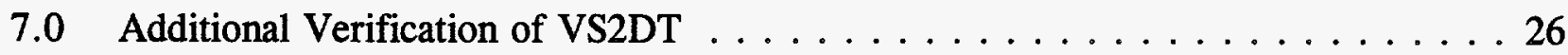

7.1 Verification Problem 1-Unsaturated Flow . . . . . . . . . 26

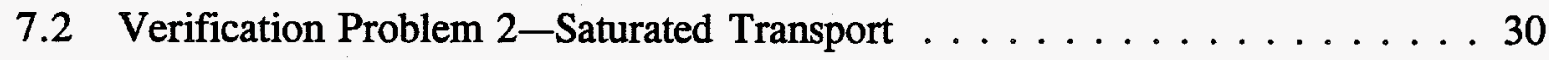

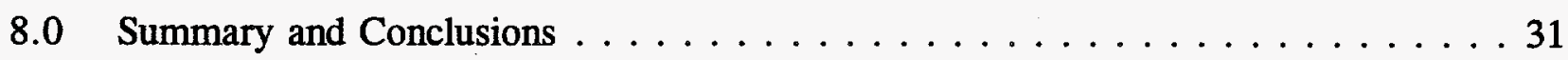

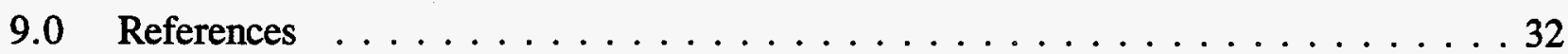




\section{List of Tables}

Table

1 Comparison of Flow-Module Features of Variably Saturated Flow and Transport Codes Proposed for Benchmarking Study

2A Boundary Conditions for Benchmark Problems 1 and 2

2B Soil Hydraulic Properties for Benchmark Problems 1 and 2

3A Boundary Conditions for Benchmark Problem 3

3B Soil Hydraulic Properties for Benchmark Problem 3

4

Mass Balance Results at 30 Days and CPU Time Required to Solve Benchmark Problem 1

Computation Time Results for Benchmark Problem 2

Computation Time Results for Benchmark Problem 3

7

Hydraulic Parameters Used in VS2DT Verification 
Figure

1

2

3

4

5

6

7

8

9

10

11

12

13

14

Title

Schematic Diagram and Geometric Description of Soil Heterogeneity Used in All Benchmarking Problems

Relative Saturation Profile at 30 Days for Benchmark Problem 1 As Predicted by VAM2D

Relative Saturation Profiles at 30 Days for Benchmark Problem 1 As Predicted by VS2DT

Relative Saturation Profiles at 30 Days for Benchmark Problem 1 As Predicted by VSAFT2

Relative Saturation Profiles at 30 Days for Benchmark Problem 1 As Predicted by DCM3D

Relative Saturation Profiles at 30 Days for Benchmark Problem 1 As Predicted by PORFLO-3, TRACR3D, and FLASH (from Magnuson et al., 1990)

Relative Saturation Profiles at 30 Days for Benchmark Problem 1 for All Seven Codes Tested

Example of Change in Moisture Content Fields That Were Numerically Integrated to Use in Mass Balance Computation

Direct Solution of Steady-State Relative Saturation Field Obtained by VAM2D for Benchmark Problem 3

Time-Marching Solution of Steady-State Relative Saturation Field Obtained by VAM2D for Benchmark Problem 3

Time-Marching Solution of Steady-State Relative Saturation Field Obtained by VS2DT for Benchmark Problem 3

Time-Marching Solution of Steady-State Relative Saturation Field Obtained by VSAFT2 for Benchmark Problem 3

Contour Plots of Unsaturated Pressure Head (cm) As Predicted by VS2DT and Philip (1989)

Contour Plots of Solute Concentration (mg/L) As Predicted by VS2DT and TDAST 
Intentionally Left Blank 


\subsection{Introduction}

The overall objective of this study was to identify the "code of choice" for use by Sandia National Laboratories/New Mexico (SNL/NM) staff in the Environmental Restoration (ER) Department when they need to simulate vadose zone flow and contaminant transport. It was felt that a code benchmarking effort was needed because many codes are available to solve such problems, but none of the codes could be identified as "the best for the job" based on reading the code documentation alone. Based on the results of the benchmarking exercise, the VS2DT code was identified as the code of choice for two-dimensional problems in which flow described by Richards equation and transport described by the advection-dispersion is deemed adequate. To provide additional assurances regarding the code's accuracy for two-dimensional flow and transport, two verification problems were run.

\subsection{Mathematical Models}

Assuming that flux rates through unsaturated media can be computed using the unsaturated form of Darcy's law and that mass balance principles are obeyed, then the Richards equation is appropriate for characterizing moisture flow:

$$
\nabla \cdot K(\theta) \nabla(\Psi+z)=\frac{\partial \theta}{\partial t}
$$

where $K(\theta)$ is the unsaturated hydraulic conductivity as a function of water content $\theta, \psi$ is the capillary pressure head, $z$ is the vertical ordinate (positive upward), and $t$ is time. A variety of formulations are typically employed to characterize the variably saturated hydraulic properties $K-\theta$ and $\theta-\psi$ relationships; in this paper we use the van Genuchten equations unless otherwise noted:

$$
S=\frac{\theta-\theta_{r}}{\theta_{s}-\theta_{r}}=\left[1+(\alpha \psi)^{n}\right]^{n /(n-1)}
$$

where $S$ is the relative water saturation, $\theta$ is the volumetric water content, $\theta_{\text {residual }}$ is the residual water content, $\theta_{s}$ is the saturated water content, and $\alpha$ and $n$ are constants obtained by fitting a measured $\theta-\psi$ curve to (2). The unsaturated hydraulic conductivity is approximated using the van Genuchten equation: 


$$
K(S)=k_{s} K_{r}(S)=k_{s} S^{1 / 2}\left(1-\left(1-S^{1 / m}\right)^{m}\right)^{2}
$$

where $k_{s}$ is the saturated hydraulic conductivity, $K_{r}$ is the relative permeabilty, $m=(n-1) / n$, and $S$ and $n$ are defined above.

To simulate solute transport, hydrogeologic modelers typically use the advection-dispersion equation:

$$
\nabla \cdot(D \nabla C)-\nabla \cdot v C=\frac{\partial C}{\partial t}
$$

where $D$ is the hydrodynamic dispersion coefficient, $v$ is the seepage velocity (Darcy velocity divided by the moisture content) vector field obtained by solution of the flow equation (1), $C$ is the solute concentration, and $t$ is time. The hydrodynamic dispesion coefficient is modeled as the sum of the aqueous diffusivity, $D^{*}$, and the mechanical dispersion coefficient, $D_{m}\left(D_{m}=\right.$ $\epsilon v$ where $\epsilon$ is the dispersivity). Although all of the codes can handle retardation and first-order decay (processes not accounted for in 4 as written), each of the codes' documentation manuals present verification problems showing the codes' abilities to accurately simulate these processes and it was deemed beyond the scope of this benchmarking study to investigate these capabilities.

\subsection{Benchmarking}

The codes tested were:

- VAM2D (version 5.1f), a proprietary finite-element flow and solute transport code developed by HydroGeoLogic, Inc. (Huyakorn et al., 1988)

- VS2DT, a finite-difference flow and solute transport code developed by the U.S. Geological Survey (USGS) (Lapalla et al., 1987; Healy, 1990)

- VSAFT, a finite-element flow and solute transport code developed at the University of Arizona (Yeh and Srivastava, 1990).

In addition to these three flow and transport codes, the variably saturated flow code DCM3D (Updegraff, 1991) was included on one of the benchmarking problems. DCM3D is an integrated finite-difference code developed at SNL/NM and is capable of simulating three-dimensional flow in a dual-continuum with dynamic mass transfer between the continua. Although it currently has no solute transport capabilities, DCM3D was included in this study to see how this highly 
sophisticated code would perform against the more traditional Richards equation flow simulators. Table 1 provides a summary comparison of the features of each of the codes used in the benchmarking study.

Three problems were selected for benchmarking the codes against each other. The first two problems investigated infiltration into heterogeneous, initially dry soils. The two were essentially the same problem in terms of geometry, material types, and boundary conditions, but they had different initial conditions. Problem 1 was originally developed as a conceptual model for an infiltration experiment conducted at the Jornada trench site near Las Cruces, New Mexico (Smyth et al., 1988). The third problem looked at steady-state flow in a heterogeneous, partially saturated soil profile. It was identical to problems 1 and 2 in terms of geometry, but it differed in terms of material properties and boundary conditions. These problems were chosen because past experience indicates that difficulties are often encountered when simulating severely nonlinear flow conditions (Huyakorn et al., 1984), such as infiltration into dry, heterogeneous soils (Hills, 1989) and steady flow in partially saturated heterogenous profiles (Kozak et al., 1990). Additionally, problem 1 was previously used in another variably saturated flow code study (Magnuson et al., 1990) that benchmarked the performance of three different codes. Thus, in problem 1 it was possible to compare the performance of seven different codes.

Figure 1 shows the geometric layout of the heterogeneous soil profile used in all three benchmarking problems. A computational grid of 1,980 nodes ( $45 \times 42$ nodes) was used to obtain the numerical solutions. Although this is slightly coarser than the 2,832-node mesh used by Magnuson et al. (1990), this study was constrained by a 2,000-element limit imposed by the VAM2D code. Table 2 summarizes the boundary conditions and soil hydraulic properties used in problems 1 and 2. These two problems differed only in the specified initial condition; for problem 1 a uniform initial pressure head was specified $\psi_{i}=-734$ centimeters $(\mathrm{cm})$ of water, while in problem 2 , a much drier $\psi_{i}=-10,000-\mathrm{cm}$ initial condition was used. Table 3 summarizes the boundary conditions and soil hydraulic properties for problem 3. 
Table 1

\section{Comparison of Flow-Module Features of Variably Saturated Flow} and Transport Codes Proposed for Benchmarking Study

\begin{tabular}{|c|c|c|c|c|c|c|c|c|c|c|}
\hline & $\begin{array}{l}\text { Code } \\
\text { Name }\end{array}$ & $\begin{array}{l}\text { Spatial } \\
\text { Dim. }\end{array}$ & $\begin{array}{l}\text { Numerical } \\
\text { Scheme }\end{array}$ & Intercell Rel. Cond. & $\begin{array}{l}\text { Nonlinear } \\
\text { Iteration }\end{array}$ & $\begin{array}{c}\text { Time Step } \\
\text { Contral }\end{array}$ & $\begin{array}{l}\text { Matrix } \\
\text { Solution }\end{array}$ & $\begin{array}{c}\text { Initial } \\
\text { Condition }\end{array}$ & $\begin{array}{l}\text { Boundary } \\
\text { Conditions }\end{array}$ & Internal Source/Sink \\
\hline & VS2DT & $\begin{array}{l}\text { 1D Column } \\
\text { 2D Profile } \\
\text { 3D } \\
\text { Axisym. }\end{array}$ & $\begin{array}{c}\text { Finite } \\
\text { Difference }\end{array}$ & $\begin{array}{l}\text { User Choice; } \\
\text { either geom. mean, } \\
\text { arithmetic mean, or } \\
\text { upstream weighting }\end{array}$ & $\begin{array}{l}\text { Newton- } \\
\text { Raphson }\end{array}$ & Automatic & $\begin{array}{l}\text { SIP Iteration } \\
\text { Algorithm }\end{array}$ & $\begin{array}{c}\text { Either head } \\
\text { or moisture } \\
\text { content }\end{array}$ & $\begin{array}{l}\text { 1. Specified Flux } \\
\text { 2. Specified head } \\
\text { 3. Infiltration } \\
\text { 4. Evaporation } \\
\text { 5. Seepage Face }\end{array}$ & $\begin{array}{l}\text { 1. } \\
\text { Evapotranspiration } \\
\text { 2. Specified Head } \\
\text { 3. Specified Flux }\end{array}$ \\
\hline & VAM2D & $\begin{array}{l}\text { 1D Column } \\
\text { 2D Plan } \\
\text { 2D Profile } \\
\text { 3D } \\
\text { Axisym. }\end{array}$ & $\begin{array}{l}\text { Finite } \\
\text { Element }\end{array}$ & $\begin{array}{l}\text { (intracell) } \\
\text { Either arith. mean or } \\
\text { upstream weighting }\end{array}$ & $\begin{array}{l}\text { Picard or } \\
\text { Newton- } \\
\text { Raphson }\end{array}$ & $\begin{array}{l}\text { Flexible; } \\
\text { Autom. or } \\
\text { User } \\
\text { Specified }\end{array}$ & $\begin{array}{c}\text { Direct } \\
\text { Gaussian } \\
\text { Elimination }\end{array}$ & $\begin{array}{c}\text { Either head } \\
\text { or moisture } \\
\text { content }\end{array}$ & $\begin{array}{l}\text { 1. Specified Flux } \\
\text { 2. Specified Head } \\
\text { 3. Infiltration } \\
\text { 4. Evaporation } \\
\text { 5. Seepage Face } \\
\text { 6. Free Drainage }\end{array}$ & $\begin{array}{l}\text { 1. } \\
\text { Evapotranspiration } \\
\text { 2. Specified Head } \\
\text { 3. Specified Flux }\end{array}$ \\
\hline & VSAFT2 & $\begin{array}{l}\text { 1D Column } \\
\text { 2D Plan } \\
\text { 2D Profile } \\
\text { 3D } \\
\text { Axisym. }\end{array}$ & $\begin{array}{l}\text { Finite } \\
\text { Element }\end{array}$ & $\begin{array}{c}\text { (intracell) } \\
\text { Arith. mean? }\end{array}$ & $\begin{array}{l}\text { Picard or } \\
\text { Newton- } \\
\text { Raphson }\end{array}$ & $\begin{array}{l}\text { Flexible; } \\
\text { Autom. or } \\
\text { User } \\
\text { Specified }\end{array}$ & $\begin{array}{l}\text { Preconditioned } \\
\text { Conjugate } \\
\text { Gradient }\end{array}$ & Head & $\begin{array}{l}\text { 1. Specified Flux } \\
\text { 2. Specified Head } \\
\text { 3. Evaporation } \\
\text { 4. Seepage Face } \\
\text { 5. Well Bore }\end{array}$ & $\begin{array}{l}\text { 1. } \\
\text { Evapotranspiration } \\
\text { 2. Specified Head } \\
\text { 3. Specified Flux }\end{array}$ \\
\hline
\end{tabular}




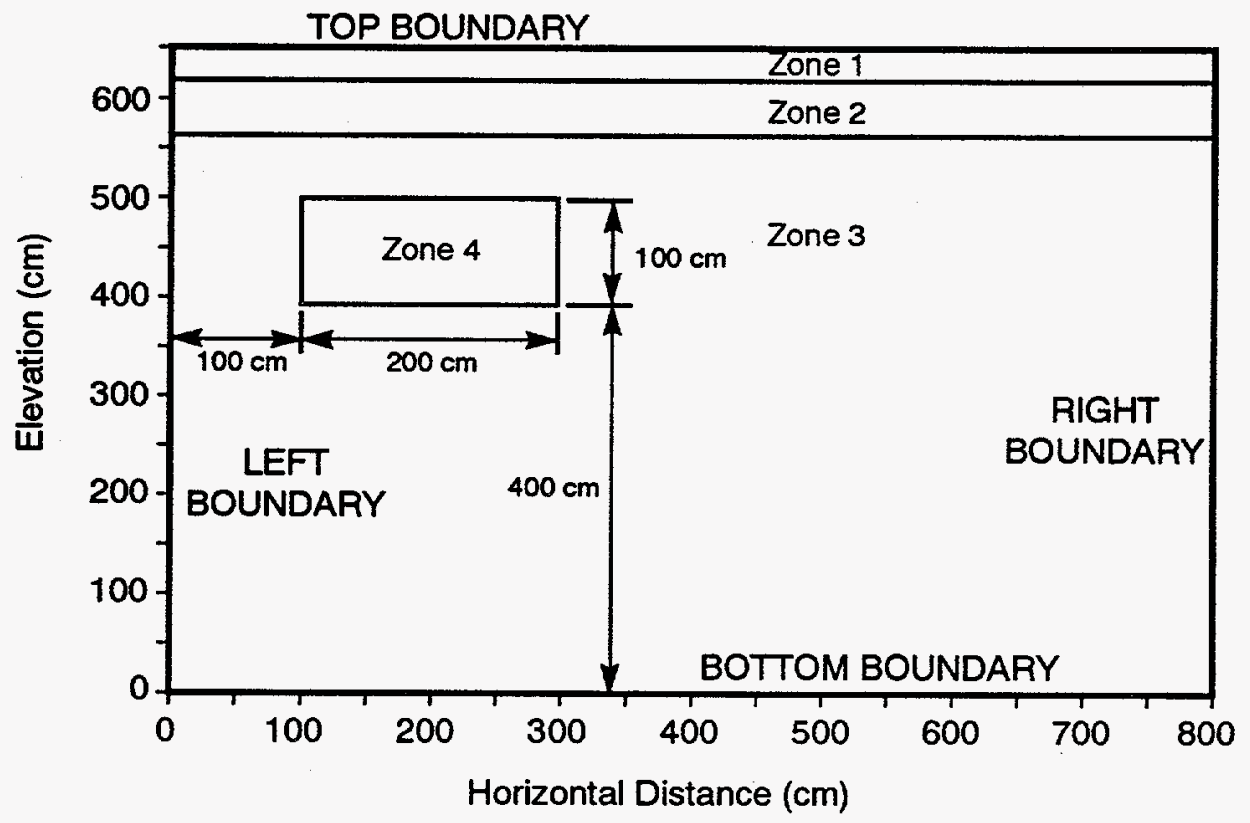

Figure 1

Schematic Diagram and Geometric Description of Soil Heterogeneity Used in All Benchmarking Problems 
Table 2a

Boundary Conditions for Benchmark Problems 1 and 2

\begin{tabular}{||c|c|c|c||}
\hline Boundary Location & Range & Boundary Condition & Value \\
\hline \hline Left-Hand Side & Entire Length & Symmetry-No Flow & $\mathrm{V}_{\mathrm{x}}=0$ \\
\hline Right-Hand Side & Entire Length & No Flow & $\mathrm{V}_{\mathrm{x}}=0$ \\
\hline Bottom & Entire Length & No Flow & $\mathrm{V}_{\mathrm{z}}=0$ \\
\hline Top & $0-225 \mathrm{~cm}$ & Specified Flux & $2 \mathrm{~cm} /$ day \\
\hline Top & $225-800 \mathrm{~cm}$ & No Flow & $\mathrm{V}_{\mathrm{z}}=0$ \\
\hline
\end{tabular}

Table 2b

Soil Hydraulic Properties for Benchmark Problems 1 and 2

\begin{tabular}{|c|c|c|c|c|c||}
\hline $\begin{array}{c}\text { Soil } \\
\text { Zone }\end{array}$ & $K_{\text {sat }}(\mathrm{cm} / \mathrm{d})$ & $\Theta_{\text {residual }}$ & $\Theta_{\text {sat }}$ & van Genuchten $a$ & $\begin{array}{c}\text { van Genuchten } \\
\mathrm{n}\end{array}$ \\
\hline \hline 1 & 790.9 & .1020 & .368 & $.0334 \mathrm{~cm}^{-1}$ & 1.982 \\
\hline 2 & 469.9 & .0985 & .351 & .0363 & 1.632 \\
\hline 3 & 415.0 & .0859 & .325 & .0345 & 1.573 \\
\hline 4 & 4150.0 & .0859 & .325 & .0345 & 1.573 \\
\hline
\end{tabular}


Table 3a

Boundary Conditions for Benchmark Problem 3

\begin{tabular}{||c|c|c|c||}
\hline Boundary Location & Range & Boundary Condition & Value \\
\hline \hline Left-Hand Side & $0-225 \mathrm{~cm}$ & Hydrostatic Sat. & $\mathrm{H}=225 \mathrm{~cm}$ \\
\hline Left-Hand Side & $225-650 \mathrm{~cm}$ & No Flow & $\mathrm{V}_{\mathrm{x}}=0$ \\
\hline Right-Hand Side & $0-200 \mathrm{~cm}$ & Hydrostatic Sat. & $\mathrm{H}=200 \mathrm{~cm}$ \\
\hline Right-Hand Side & $200-650 \mathrm{~cm}$ & No Flow & $\mathrm{V}_{\mathrm{x}}=0$ \\
\hline Bottom & Entire Length & No Flow & $\mathrm{V}_{\mathrm{z}}=0$ \\
\hline Top & Entire Length & Specified Flux & $0.1 \mathrm{~cm} /$ day \\
\hline
\end{tabular}

Table 3b

Soil Hydraulic Properties for Benchmark Problem 3

\begin{tabular}{|c|c|c|c|c|c||}
\hline $\begin{array}{c}\text { Soil } \\
\text { Zone }\end{array}$ & $\mathrm{K}_{\text {sat }}(\mathrm{cm} / \mathrm{d})$ & $\Theta_{\text {residual }}$ & $\Theta_{\text {sat }}$ & $\begin{array}{c}\text { van Genuchten } \\
a\end{array}$ & van Genuchten $\mathrm{n}$ \\
\hline \hline 1 & 79.090 & .1020 & .368 & $.0334 \mathrm{~cm}^{-1}$ & 1.982 \\
\hline 2 & 46.990 & .0985 & .351 & .0363 & 1.632 \\
\hline 3 & 2.000 & .0859 & .325 & .0345 & 1.573 \\
\hline 4 & 0.004 & .0859 & .325 & .0250 & 1.573 \\
\hline
\end{tabular}

For all problems, convergence at each time step was specified to occur when the maximum nodal head change between two successive iterations was less than $0.1 \mathrm{~cm}$ water for both VS2DT and VSAFT2. VAM2D uses a telescoping, head-dependent iteration convergence criteria: 


$$
T O L_{t, n}=H T O L+R E L C O N * \psi_{t, n}
$$

where $T O L_{t, n}$ is the head iteration convergence tolerance at time level $t$ for node $n, H T O L$ is the minimum head iteration convergence tolerance, RELCON is the relative head iteration convergence tolerance, and $\Psi_{t, n}$ is the pressure head at node $n$ at the current time level $t$. This approach is intended to accelerate convergence for problems involving infiltration into very dry soils. For the benchmarking problems reported here, HTOL and RELCON were set to $0.1 \mathrm{~cm}$ water and 0.0015 , respectively.

One other issue regarding benchmark problem formulation involves how the various codes compute interblock conductances. The type of averaging scheme selected will affect the convergence properties of the code, and recent research (Kung, 1991) underlines the physical importance of this computation issue when modeling unsaturated systems. For the finite element approach employed in VAM2D and VSAFT2, each element is homogeneous in terms of saturated conductivity, but since the pressure varies across an element, the relative permeability will also vary. VAM2D can use either an arithmetic mean or upstream-weighted relative permeability, but VSAFT2 uses only an arithmetic mean value. In the block-centered finite difference approach employed by VS2DT, an interblock conductance (involving both the saturated conductivity and the relative permeability) must be computed for each node in the construction of the finite difference equations. The VS2DT user is offered the option of using either upstream-weighted, arithmetic mean, or geometric mean values for the interblock relative permeability. VS2DT always uses a harmonic mean for interblock-saturated conductivity. Detailed investigations on interblock conductance formulas used in finite difference models indicate that the harmonic mean is the most appropriate value to use for saturated systems (Appel, 1976) and that the geometric mean introduces the least error for unsaturated systems (Haverkamp and Vauclin, 1979). In benchmark problem 1, all three interblock conductance options for VS2DT were tested. The integrated finite difference formulation used by DCM3D also requires the computation of interblock conductances. The code currently uses only a harmonic mean conductance on the entire unsaturated conductivity term (Updegraff, 1991).

\subsection{Benchmarking Results}

Several criteria were considered to allow an objective comparison of code performance. Quantitative criteria included CPU time to solve all of the problems and mass balance errors for one of the transient problems. Reported CPU times are for an IBM-compatible personal 
computer with a $486 / 33$ processor. Qualitative factors considered included code documentation, level of quality assurance in code development, availability of the source code, code "ease-ofuse," and number of options and capabilities of the codes.

All of the codes successfully converged on a solution for each of the benchmarking problems. Although all the codes appeared to give qualitatively similar results, a quantitative measure of the differences between each of the solutions was developed. Furthermore, the CPU time required to solve the various problems varied greatly from code to code.

\subsection{Benchmark Problem 1-Infiltration Into Dry Soils}

Recall that problem 1 tested the codes' abilities to simulate infiltration into a dry, heterogeneous soil profile. The pressure-head fields predicted by each of the codes looked alike. Similarly, the relative water saturation fields at 30 days predicted by VAM2D, VS2DT, VSAFT2, and DCM3D and presented in Figures 2, 3, 4, and 5, respectively, also possessed qualitative agreement. Figure 6 shows the corresponding water saturation field for the same problem predicted by TRACR3D, FLASH, and PORFLO-3, as reported in the benchmarking study by Magnuson (1990). They too bear a strong qualitative resemblance to the predictions of VAM2D, VS2DT, VSAFT2, and DCM3D. While all seven codes predict more or less the same response of the soil profile to the applied surface flux (Figure 7), the fact that there are quantitative differences may cause one to ask, "which is the right prediction?" While one can not unequivocally answer that question, some quantitative measures can be developed to assess the consistency of the numerical solutions. One such measure is the mass balance error.

For this problem, with no-flow boundaries everywhere except along the specified flux ("infiltration") boundary, the integrated difference between the initial moisture content field and the moisture content field at time $t$ should equal the time integral of the applied flux between times $t_{0}$ and $t$. Each of the codes tested have mass balance computation routines, and each of the codes' internal mass balance routines indicate mass balance errors smaller than 1 percent of the total infiltrated volume. However, the saturation fields (Figures 2 through 7) obviously suggest greater than a 1 percent difference between the various codes predictions of volume of water stored in the profile.

To 'reconcile this apparent inconsistency, each of the codes' predicted change in moisture content fields at $t=30$ days $(\Theta(x, z, t=30)-\Theta(x, z, t=0))$ were numerically integrated using Trapezoidal Rule, Simpson's Rule, and Simpson's 3/8 Rule algorithms to obtain estimates of the increase in 


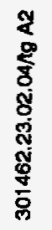

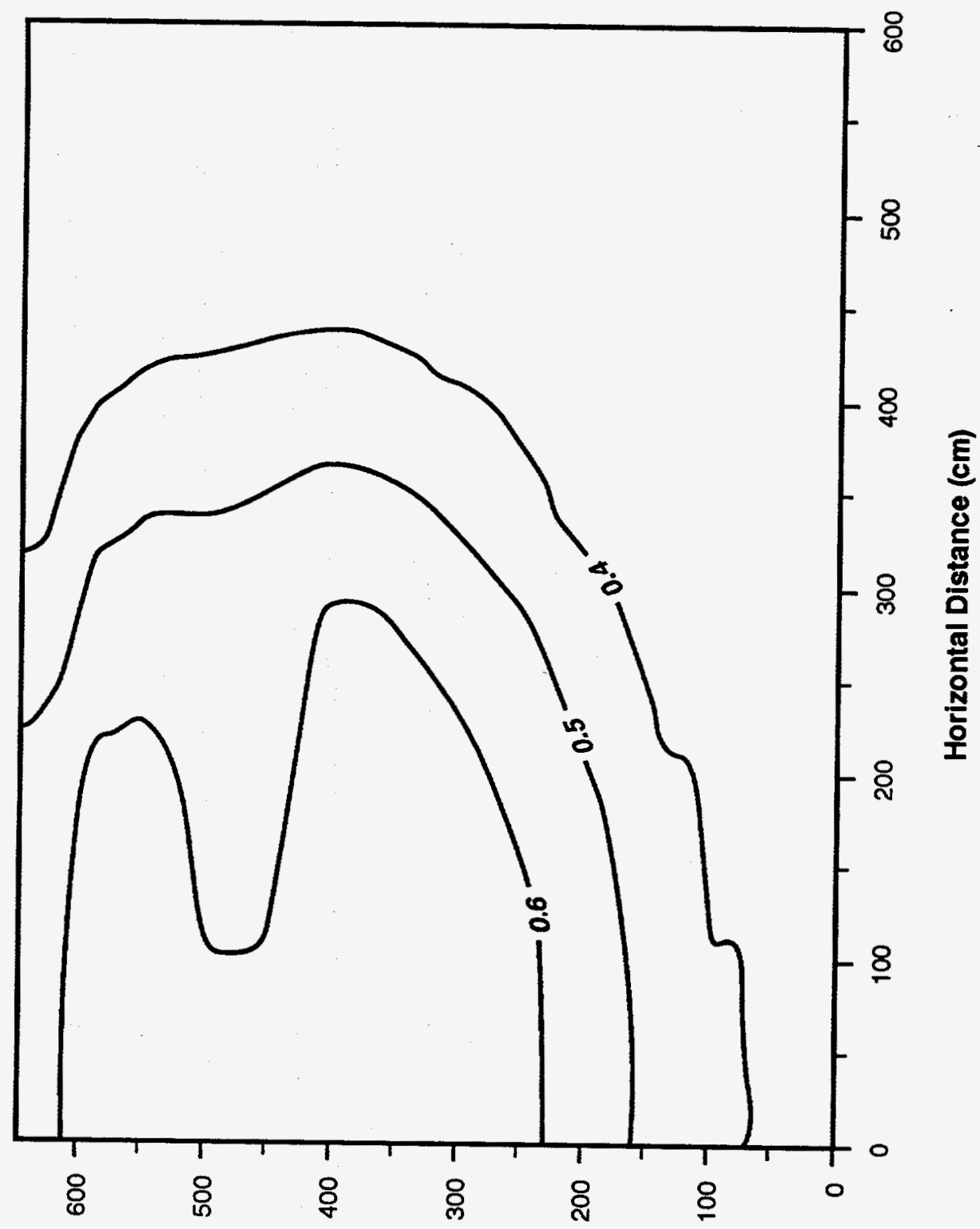

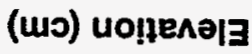

Figure 2

Relative Saturation Profile at 30 Days for Benchmark Problem 1 As Predicted by VAM2D 


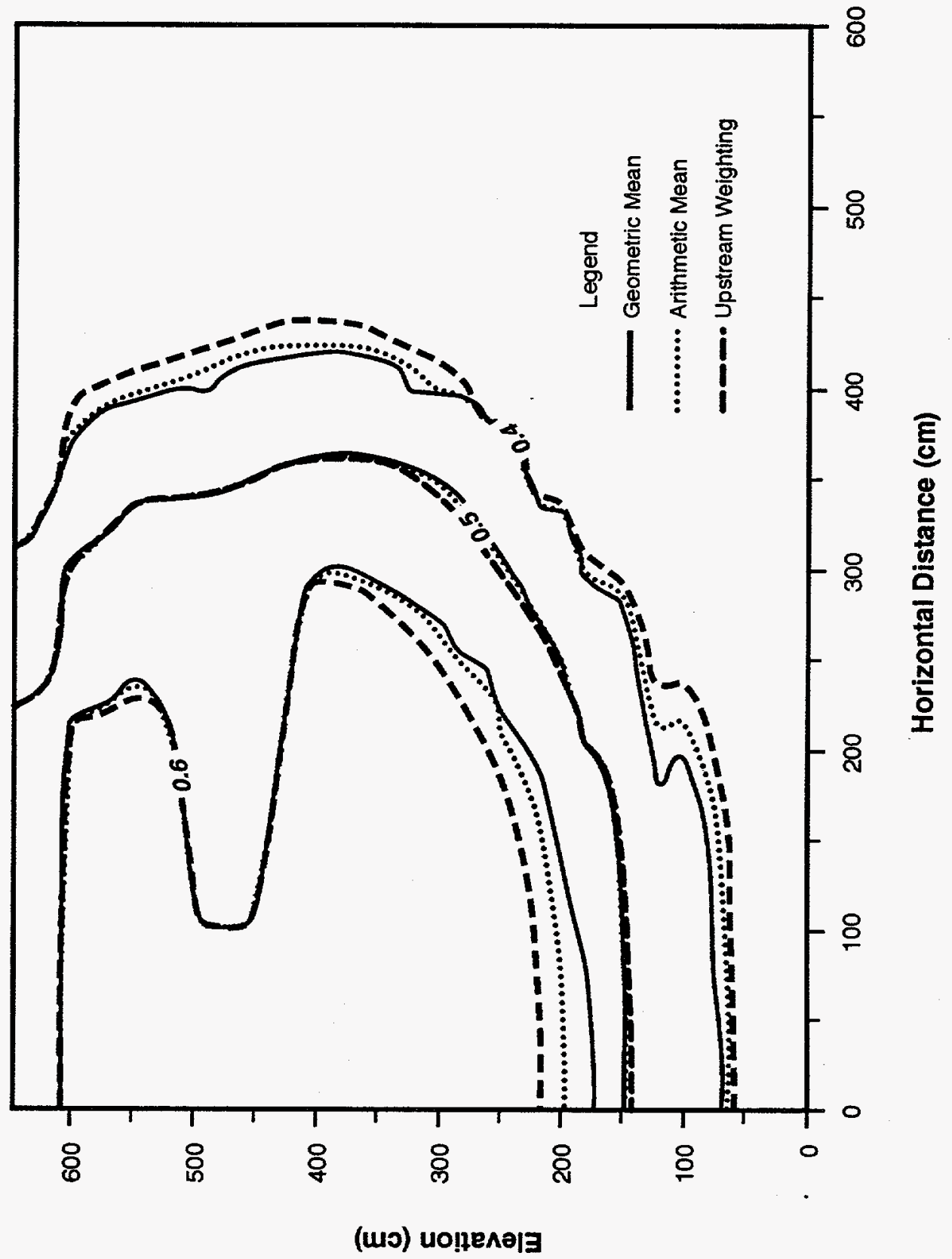

Figure 3

Relative Saturation Profiles at 30 Days for Benchmark Problem 1 As Predicted by VS2DT 


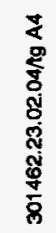

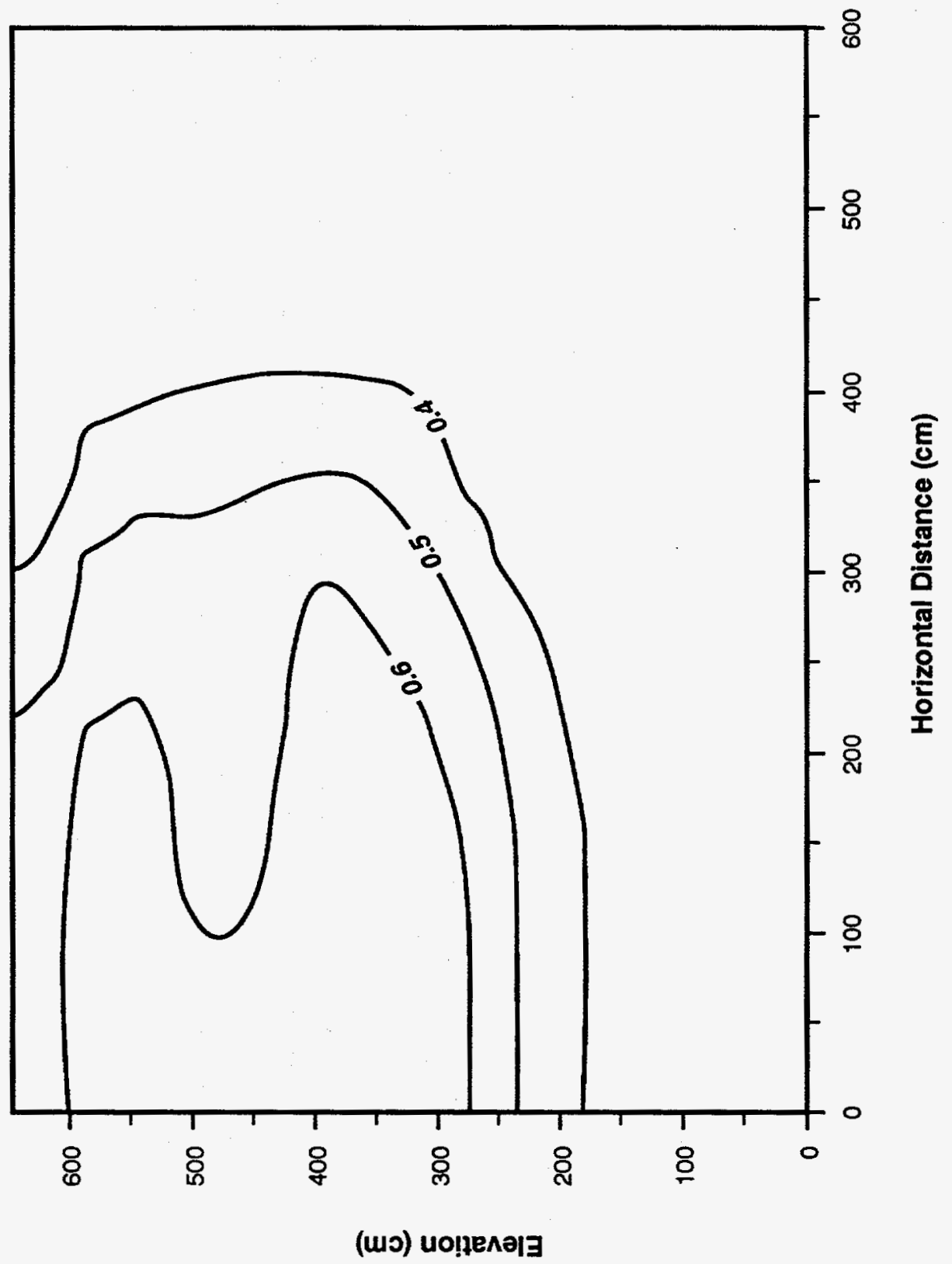

Figure 4

Relative Saturation Profiles at 30 Days for Benchmark Problem 1 As Predicted by VSAFT2

6622/91_1526.W51

12 


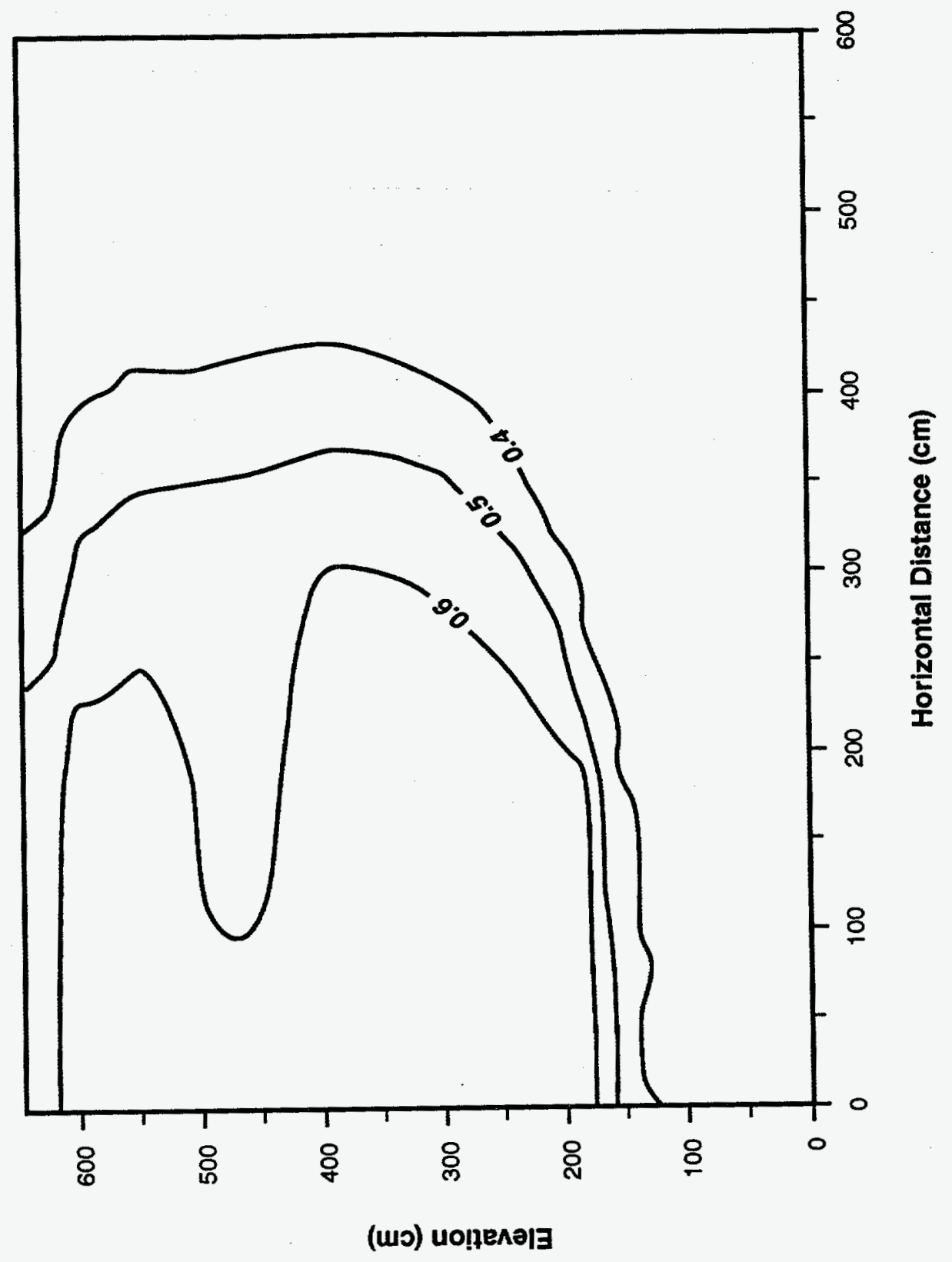

Figure 5

Relative Saturation Profiles at 30 Days for Benchmark Problem 1 As Predicted by DCM3D 


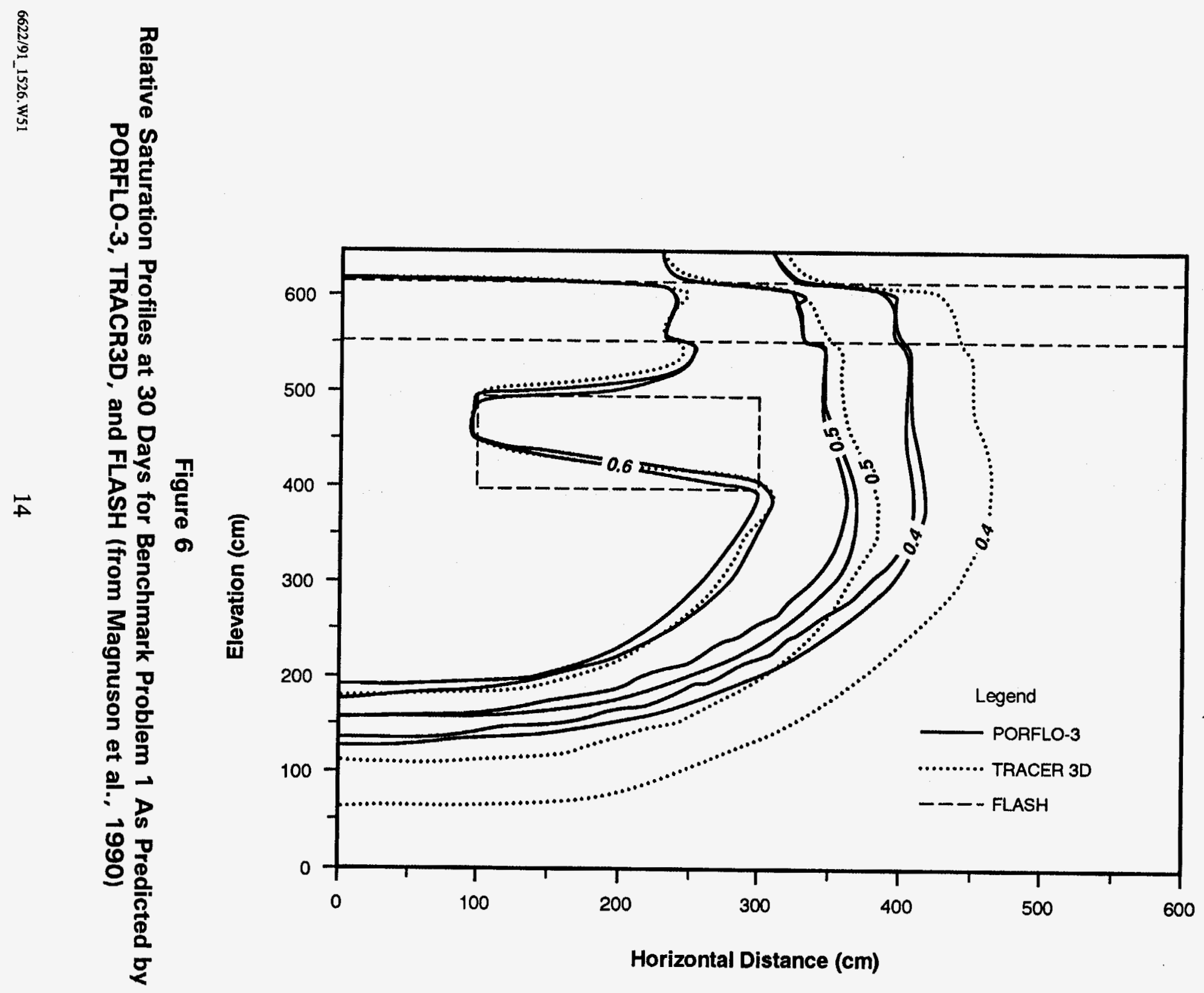

301 462.23.02.04/g A7 


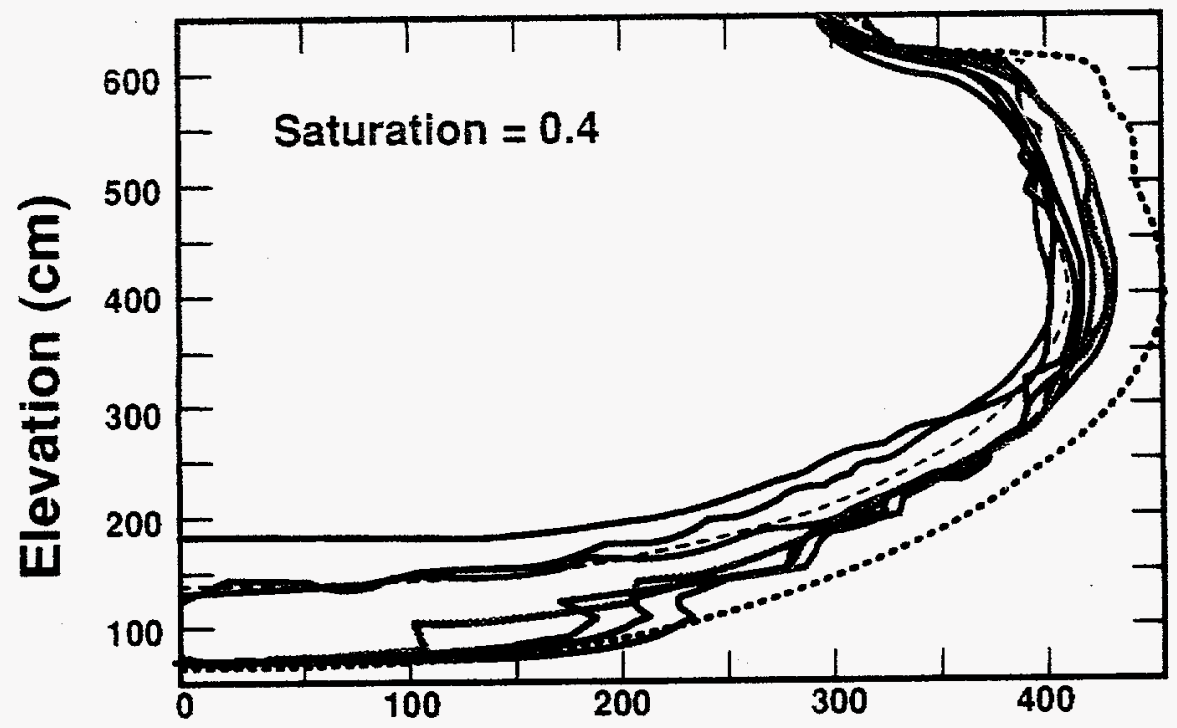

Legend:

VS2DT - Geom Mean K

VS2DT - Arith. Mean K

VS2DT - Upstream K

DCM3D

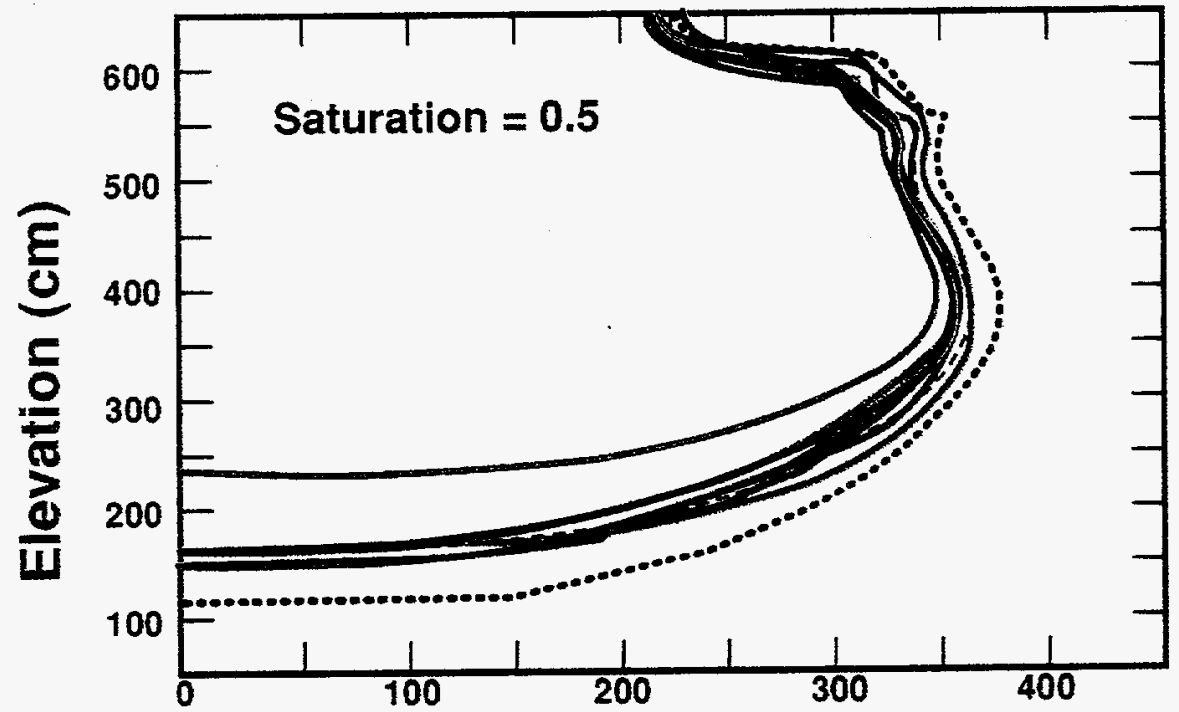

VSAFT2

VAM2D

Porflo-3 -

Flash

Tracer 3D

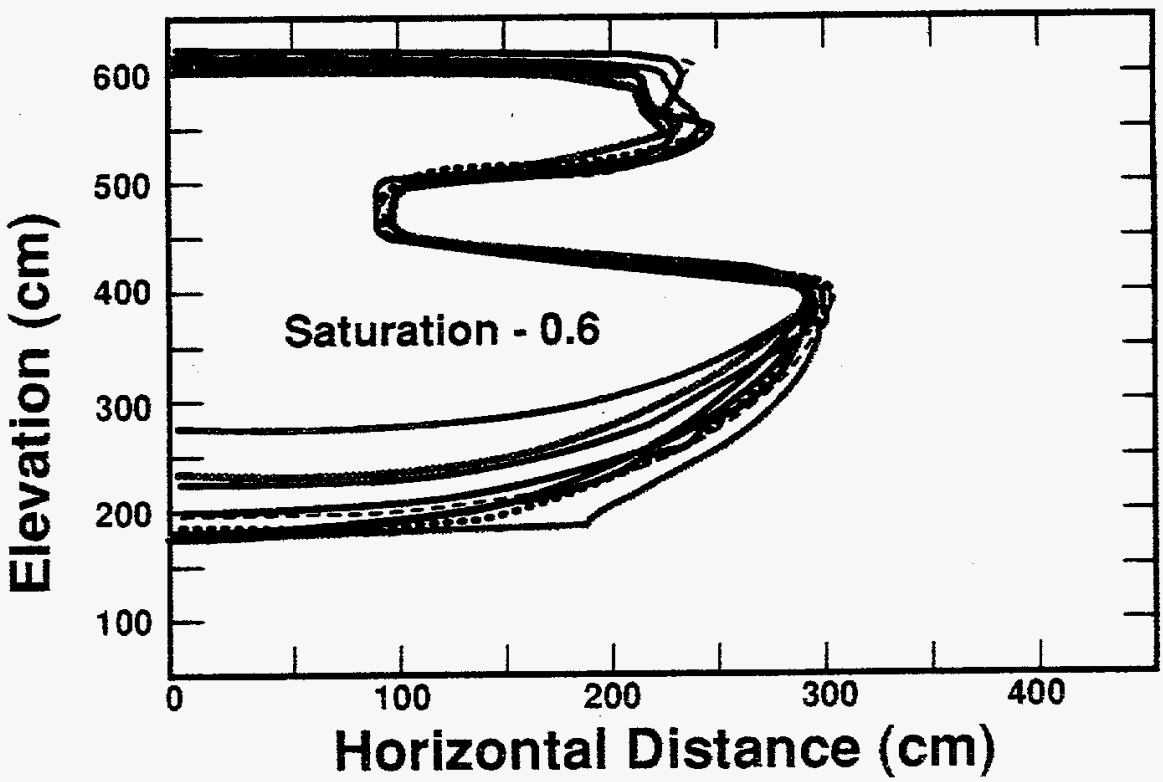

Figure 7

Relative Saturation Profiles at 30 Days for Benchmark Problem 1 for All Seven Codes Tested 


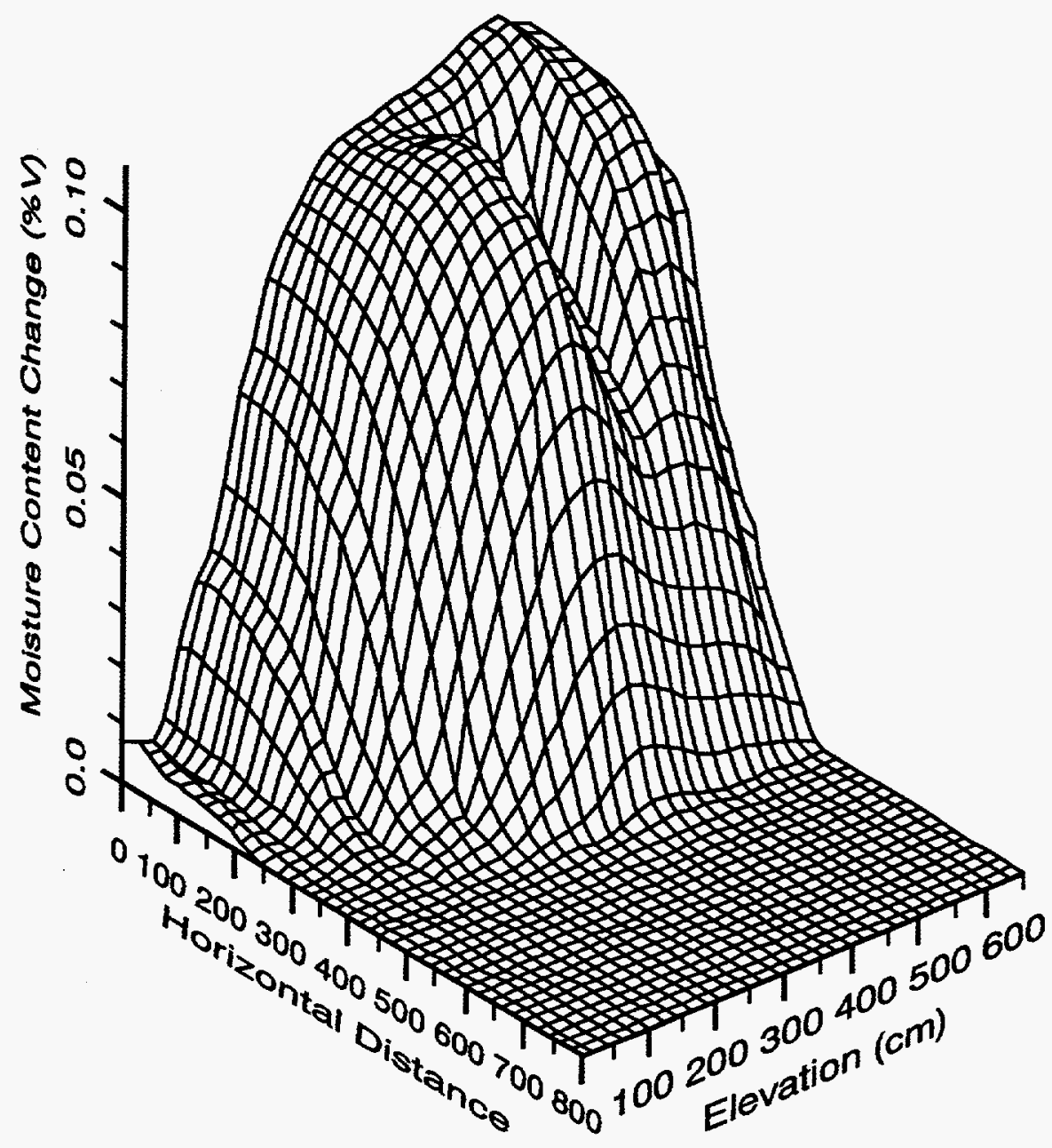

Figure 8

Example of Change in Moisture Content Fields That Were Numerically Integrated to Use in Mass Balance Computation 
Table 4

Mass Balance Results at 30 Days and CPU Time Required to Solve Benchmark Problem 1

\begin{tabular}{|c|c|c|}
\hline Code / Mode & Mass Balance Error & CPU Time (seconds) \\
\hline \hline VAM2D / Upstream K & $7.3 \%$ & $4,160.49$ \\
\hline VS2DT / Upstream K & $8.5 \%$ & 494.61 \\
\hline VS2DT / Arithmetic Mean K & (Not computed) & 560.02 \\
\hline VS2DT / Geometric Mean K & $1.7 \%$ & 610.00 \\
\hline VSAFT2 & $19.2 \%$ & $3,048.86$ \\
\hline DCM3D & $0.1 \%$ & $5,250.00$ \\
\hline
\end{tabular}

the volume of water stored in the profile. Figure 8 graphically shows an example of the change in moisture content fields that were numerically integrated. Then the average volume estimate was subtracted from the time-integrated specified surface flux, and the resulting difference was normalized by the time-integrated surface flux to obtain a measure for the mass balance error for each of the codes. Table 4 presents the results of this mass balance computation. The DCM3D results exhibited by far the smallest mass balance error $(<<1$ percent) based on this estimation procedure. The VS2DT simulation using a geometric mean interblock conductance had the second smallest mass balance error ( $~ 2$ percent), the VS2DT/upstream-weighted K and the VAM2D (which also used an upstream-weighted $\mathrm{K}$ ) results were next (errors on the order of 8 percent), and VSAFT2 prediction exhibited by far the worst mass balance error ( $\sim 19$ percent). The superiority of the DCM3D results can probably be attributed to the timecontinuous approach the code takes to solve the Richards equation. Rather than employing a finite difference approximation to the time derivative (as all the other codes in this study use), DCM3D computes time-step sizes such that the dependent variables and coefficients are quasicontinuous in time. Thus, the ordinary differential equations obtained for each time step can be solved consistently using the ODEPACK (Hindmarsch, 1983) programs. Both VAM2D and VS2DT discretize the time-dependent terms using finite differences, and they employ mass lumping and moisture capacity formulations that have been shown to provide superior mass balance results (Cooley, 1983; Milly, 1985; Celia et al., 1990). VSAFT2 also uses a finite 
difference in time and mass lumping, but the moisture capacity is incorporated into the timederivative term using a formulation that has poor mass balance characteristics (Milly, 1985). ${ }^{1}$

The other quantitative performance measure used was CPU time required to solve the problem. Table 4 also presents the CPU time results. As shown in Table 4, VS2DT was by far the fastest code on this problem, followed by VSAFT2, then VAM2D, and the slowest was DCM3D. These CPU time results, for the most part, are easily explained. VS2DT and VSAFT2 both use iterative equation solvers (the Strongly Implicit Procedure in VS2DT and a Preconditioned Conjugate Gradient algorithm in VSAFT2), while VAM2D uses a direct matrix solver. For problems of this size $(-2,000$ nodes) and larger, an iterative solver should offer significant computational savings over a direct solver. Even though VSAFT2 uses a highly efficient iterative equation solver, it is significantly slower than VS2DT, because it performs an additional finite element computation to obtain a space-continuous velocity field (Yeh and Srivistava, $1990)^{2}$. And finally, DCM3D probably is slower than the rest for the same reason that it conserves mass better than the rest: the internal time-marching criteria used by the code resulted in DCM3D taking roughly 20 times the number of time steps as the other codes to reach the end of the 30-day simulation.

\subsection{Benchmark Problem 2-Infiltration Into Very Dry Soils}

Problem 2 was exactly the same as Problem 1, except the initial condition was changed from $\Psi_{\mathrm{i}}=-734 \mathrm{~cm}$ water to $-10,000 \mathrm{~cm}$ water. This much drier initial condition provided a much more difficult convergence problem than the Problem 1 initial condition. All of the codes obtained saturation profiles at 30 days, which were somewhat similar to those depicted in Figures 2 through 7, but which again showed quantitative differences between each of the codes predictions. No mass balance check was performed for this problem. CPU time results for Problem 2 are presented in Table 5. Once again VS2DT was by far the fastest, followed by VSAFT2, followed by VAM2D. DCM3D was not used in Problem 2.

\footnotetext{
${ }^{1}$ Based on an informal transmittal of the results of this benchmarking study to Dr. Jim Yeh, University of Arizona, the formulation in VSAFT was modified. Recent work by Yeh et al. (1993) indicates that the mass balance problems with VSAFT have been resolved.

${ }^{2}$ Conversely, VAM2D directly computes its velocity field using the head-field solution. While this offers significant computational savings over the finite element computation employed by VSAFT2, the resulting velocity field is discontinuous in space. This may adversely affect subsequent solution of the solute transport problem if the spatial discretization is too coarse.
} 
Table 5

Computation Time Results for Benchmark Problem 2

\begin{tabular}{|c|c|}
\hline Code / Mode & CPU Time (seconds) \\
\hline \hline VAM2D / Upstream K & $19,076.51$ \\
\hline VS2DT / Geometric Mean K & $2,593.03$ \\
\hline VSAFT2 & $6,814.22$ \\
\hline
\end{tabular}

\subsection{Benchmark Problem 3-Steady Flow Problem}

Problem 3 was designed to test the codes' abilities to solved steady-state saturated/unsaturated flow problems for heterogeneous media. A summary of the problem geometry, soil types, and boundary conditions can be found by perusing Figure 1 and Table 3 .

VAM2D and VSAFT include an option to directly solve the steady-state form of the Richards equation. The other code (VS2DT) obtains a steady-state solution by time marching to the answer. VS2DT determines steady-state convergence by checking if the head change between any two successive time steps is less than a specified threshold value. VAM2D and VSAFT2 can also use the time-marching approach if the direct steady-state simulation approach fails.

Solutions to Problem 3 were obtained by both direct simulation of the steady flow equation and by time marching to a steady state. The first attempt was to directly obtain the steady-state solution using both VAM2D and VSAFT2. Although VSAFT2 failed to converge on a solution, VAM2D managed to obtain a solution. The relative saturation field for the VAM2D direct steady-state solution is presented in Figure 8 . Note that the low-conductivity layer (located at $100<\mathrm{x}<300 \mathrm{~cm}$ and $400<\mathrm{z}<500 \mathrm{~cm}$ ) reaches only 75 percent saturation, even though the applied surface flux rate is 25 times higher than the layer's saturated hydraulic conductivity (see Table 3). This suggests the VAM2D solution obtained by direct simulation of the steady flow equation may be in error. Steady-state saturation fields obtained by time marching using all three codes are presented in Figures 10 through 12 . All three model predictions are in nearly exact agreement down to $z=460 \mathrm{~cm}$; below that depth slight differences can be noted. All three solutions appear to be internally consistent in that the applied surface flux plus the inflow below the water table at the left boundary are balanced by the outflow beneath the water table 


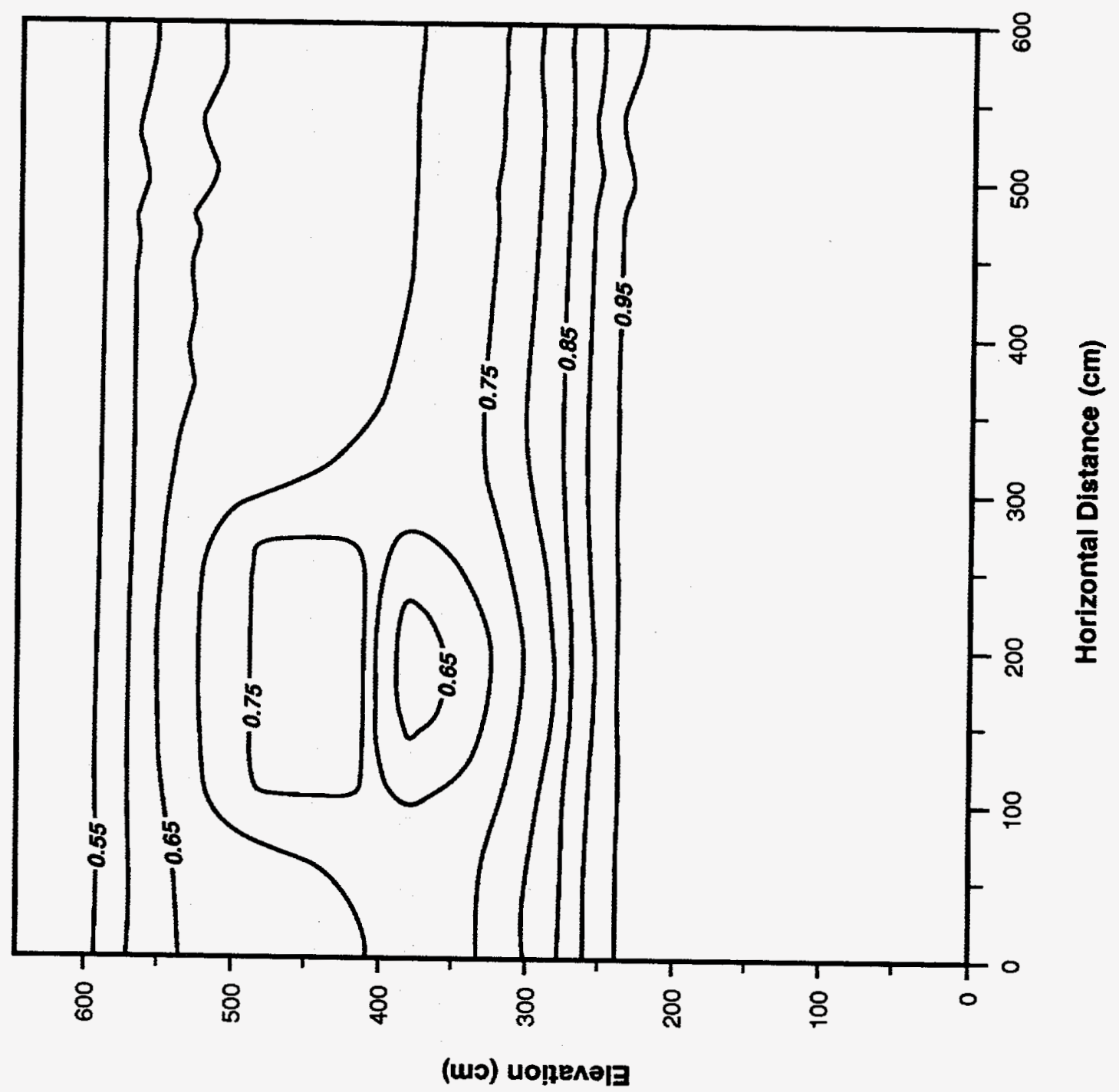

Figure 9

Direct Solution of Steady-State Relative Saturation Field Obtained by VAM2D for Benchmark Problem 3 


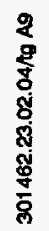

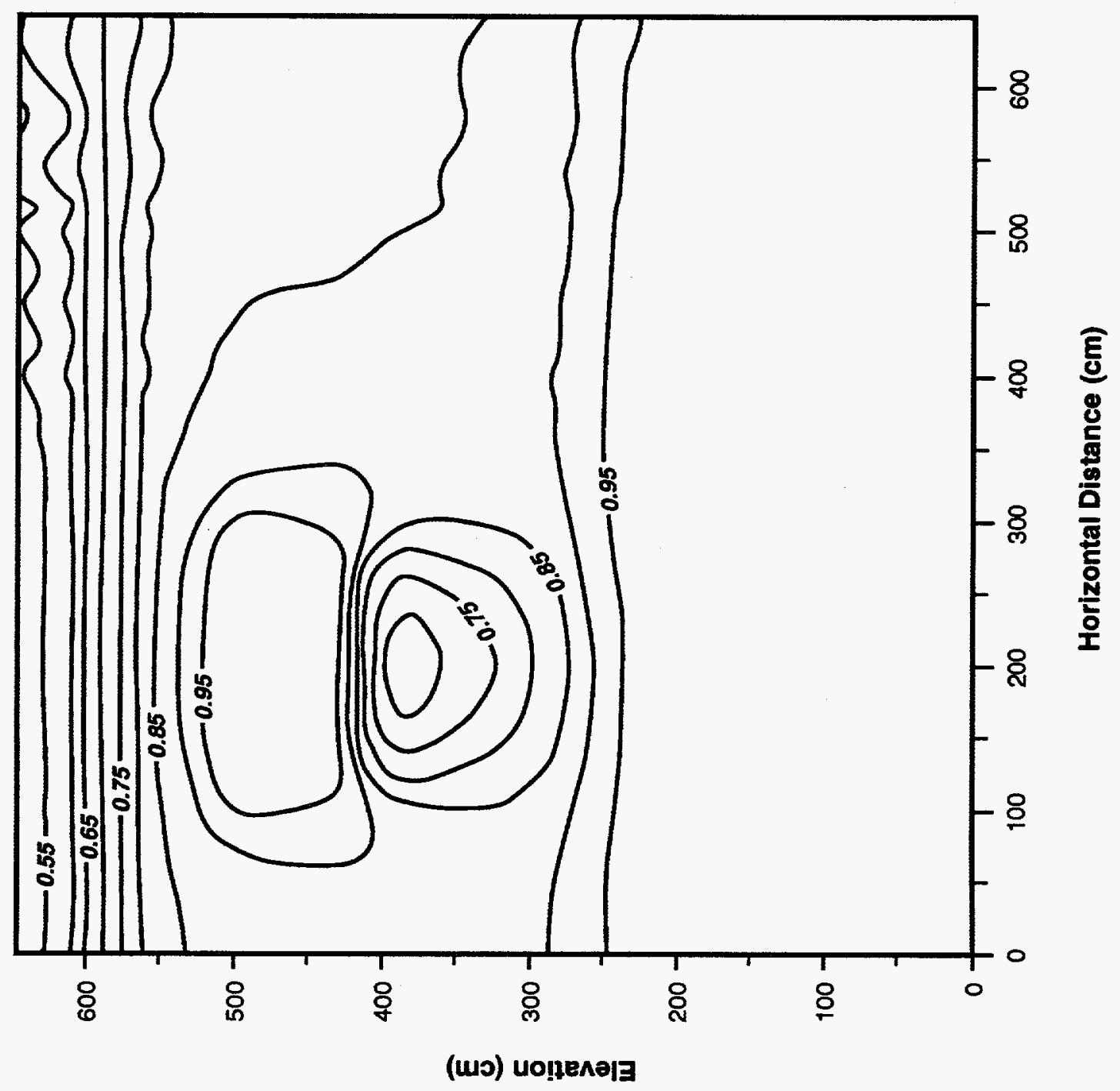

Figure 10

Time-Marching Solution of Steady-State Relative Saturation Field Obtained by VAM2D for Benchmark Problem 3 


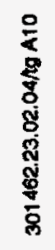

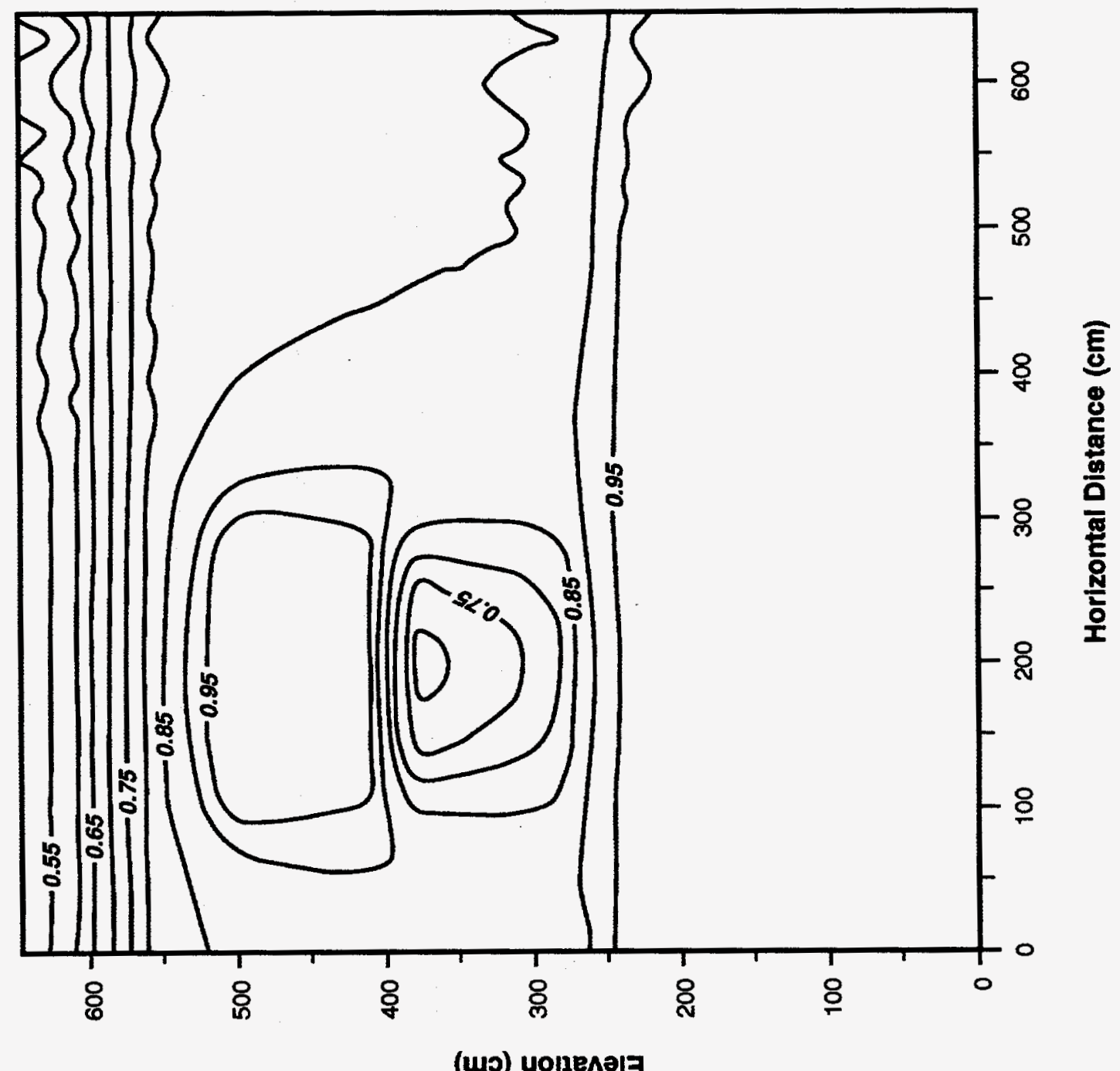

Figure 11

Time-Marching Solution of Steady-State Relative Saturation Field Obtained by VS2DT for Benchmark Problem 3 
Table 6

Computation Time Results for Benchmark Problem 3

\begin{tabular}{|c|c|}
\hline Code / Mode & CPU Time (seconds) \\
\hline \hline VAM2D-Direct Steady-State (SS) & 590.15 \\
\hline VAM2D-Time March to SS & $4,700.08$ \\
\hline VS2DT-Time March to SS & 991.07 \\
\hline VSAFT-Time March to SS & $5,953.48$ \\
\hline
\end{tabular}

at the right boundary. The CPU times required to obtain the steady flow solutions are presented in Table 6. Once again VS2DT is far faster then the other two, with VAM2D coming in second and VSAFT2 a close third.

\subsection{Qualitative Factors Comparison}

\section{1 Code Documentation and Ease of Use}

All three codes have ample documentation, which allows the user to begin applying the codes relatively quickly. The VAM2D and VS2DT documentation offers a greater depth and breadth of information than does the VSAFT2 documentation.

In terms of code ease of use, VS2DT is clearly superior to the competition. VS2DT takes freeformatted input and requires only a small number of parameters on each line of input. This allows the user to add his or her own descriptive verbiage on the right side of the input file. Thus the user can gain much information from an input data file by simply looking at the input data file. Both VSAFT2 and VAM2D users suffer from having to develop a formatted data file. VAM2D has the additional disadvantage that several of the input lines contain as many as 15 parameters; thus, the line is packed all the way through column 80 . This leaves no room for line descriptions on the right-hand side (for a conventional 80-column computer display), so the user must constantly refer to the input instructions and "count columns" when generating or debugging an input file. Furthermore, the finite element codes (particularly VAM2D) put too much burden on the user in generating the finite element mesh and assigning elemental material properties. Both finite element codes could greatly benefit from preprocessors developed to generate the input files. 


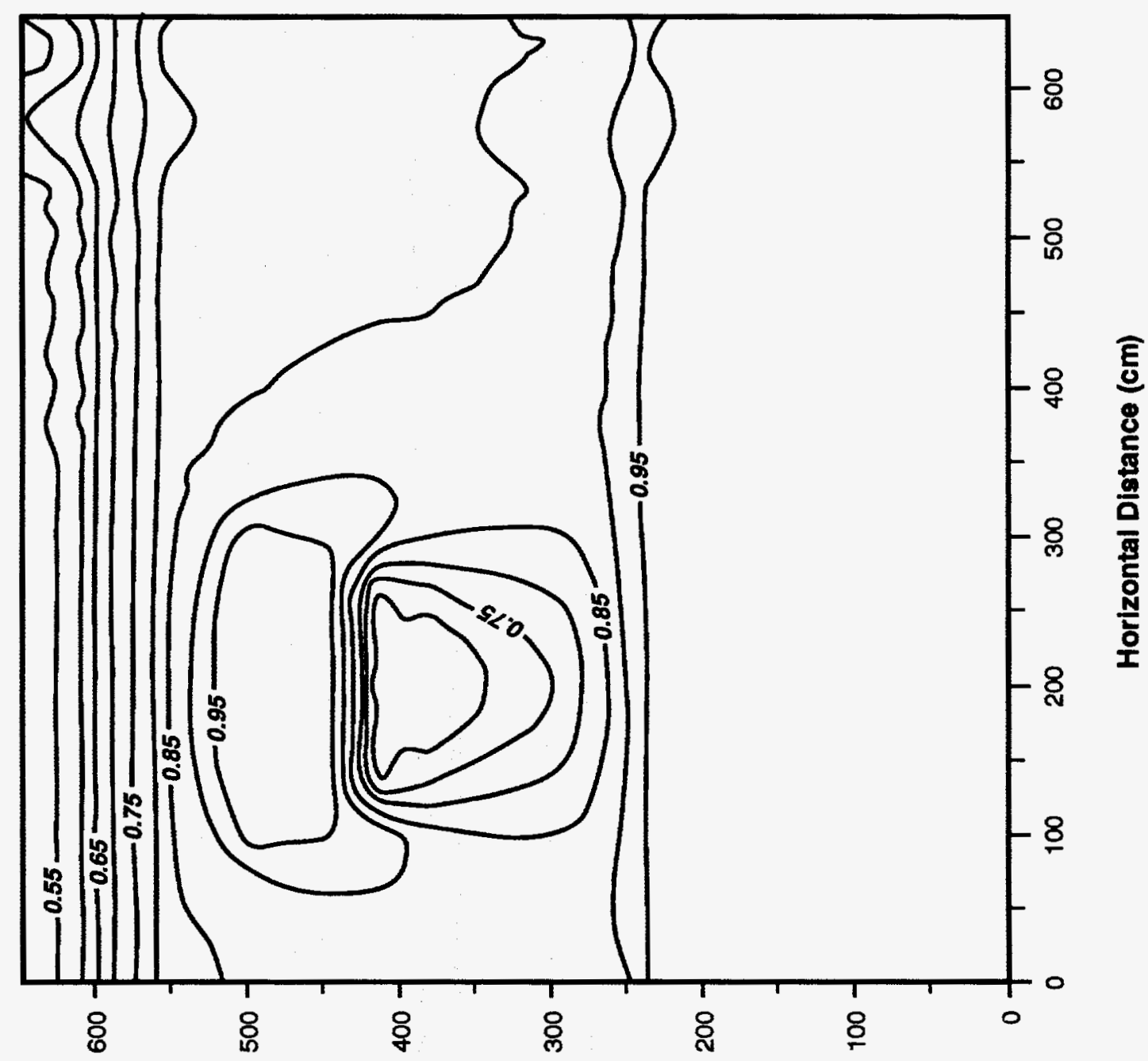

(wo) uonenala

Figure 12

Time-Marching Solution of Steady-State Relative Saturation Field Obtained by VSAFT2 for Benchmark Problem 3 


\subsection{Availability of the Source Code}

Both VS2DT and VSAFT2 source codes are available for use and/or modification merely by writing to the authors. VAM2D is a proprietary code, and the source code is unavailable.

\subsection{Level of Quality Assurance in Code Development}

The VAM2D code was developed by a private consulting company and was subject to the company's own internal quality assurance (QA) procedures. It has been tested and verified against several analytical solutions. In using the VAM2D code over the past several years, SNL/NM staff have uncovered many errors and bugs; usually the code developers fixed the bugs immediately after they were notified. The fact that bugs exist is not a major strike against VAM2D, because one should expect all codes of equivalent sophistication to contain some bugs. Unfortunately, finding and identifying bugs is made more difficult due to the unavailability of the source code; this is a major problem with VAM2D.

The VS2DT code was developed by the USGS under their software QA standards. It has been tested and previously verified against several analytical solutions (Healy, 1990). The fact that it has been released by the USGS for public use indicates a degree of confidence in the quality of VS2DT on the part of that agency. The source code is readily available for inspection and testing.

The VSAFT2 code was developed by academic researchers and tested and verified against several analytical solutions. The fact that it was developed as a research tool suggests that the code's QA standards are probably somewhat less than those of VS2DT. However, the source code is readily available for inspection and testing, which would greatly facilitate any required postdevelopment QA testing and documentation.

\subsection{Additional Options and Capabilities}

All of the codes solve both the Richards equation for flow and the advection-dispersion equation for transport. In terms of flow, all of the codes can handle seepage faces, plant-root uptake, surface-ponding infiltration, and profile-limited evaporation. Additional flow-problem features available in VAM2D are hysteresis in the soil-moisture characteristics (Kool and Parker, 1987), a free-drainage boundary condition (McCord, 1991), and state-dependent anisotropy in unsaturated conductivity (McCord et al., 1991). With regard to the transport problem, all of the codes can consider first-order decay and retardation. VS2DT has the additional transport options of modeling retardation as described by Freundlich or Langmuir isotherms and ion 
exchange. VAM2D can additionally handle multicomponent/multispecies transport and radioactive decay chains.

Thus, we see that VAM2D has the greatest versatility in term of variety of problems that it can address. Both VS2DT and VSAFT2, however, are extremely powerful tools in their own right.

\subsection{Conclusions from Benchmarking}

Based on the above quantitative and qualitative evaluations, the authors of this report recommend VS2DT for the SNL/NM ER staff to use when assessing vadose zone problems. Its versatility, ease of use, ample documentation, and far superior performance in terms of CPU time make it the hands-down winner. Although it is currently useful for a wide variety of problems, it would be enhanced greatly if features such as hysteresis, state-dependent anisotropy, free-drainage boundaries, and radioactive decay chain transport were added to the code.

Although VAM2D and VSAFT2 are powerful vadose zone flow and transport simulators, their lackluster performance compared to VS2DT and their lack of documentation in terms code development QA make them less attractive. The unavailability of the VAM2D source code provides an additional point against its selection.

\subsection{Additional Verification of VS2DT}

Healy (1990) provided several verification examples in the VS2DT manual; however, it was felt that some additional, independent verification was in order prior to giving an unequivocal recommendation to the ER staff to use VS2DT. Two verification problems were selected based on two analytical solutions, one for two-dimensional flow and one for two-dimensional transport. Comparison between VS2DT and the analytical solution was based on visual inspection of the output and quantitative comparison of the code's ability to accurately conserve the mass of the dependent variable. For the purpose of this study, the code was assumed to be verified if the difference in mass between VS2DT and the analytical solution was less than 2 percent.

\subsection{Verification Problem 1-Unsaturated Flow}

This problem represented two-dimensional unsaturated flow from a line source to a water table and was solved analytically by Philip (1989). Philip determines hydraulic conductivity as a function of tension with the following equation:

$$
K(\psi)=K_{s a t} e^{\alpha \psi}
$$


where $\psi$ is the tension, $\mathrm{K}_{\text {sat }}$ is the saturated hydraulic conductivity, and $\alpha$ is the sorptive number (Batu and Gardner, 1978). For a line source at $(x=0, z=0)$ of strength $q$ per unit length, with a water table at depth $Z_{w}$, the pressure head can be computed as:

$$
\psi(x, z)=\frac{1}{\alpha} \ln \left\{\frac{\alpha q}{K_{\text {sat }}}\left[K_{o}(r)-K_{o}\left(r_{1}\right)\right]+e^{\alpha\left(z-z_{w}\right)}\right\}
$$

where $\mathrm{x}$ and $\mathrm{z}$ are the horizontal to vertical positions,

$$
r=\frac{\alpha}{2} \sqrt{x^{2}+z^{2}}, \quad r_{1}=\frac{\alpha}{2} \sqrt{x^{2}+\left(z-2 z_{w}\right)^{2}}
$$

and $\mathrm{K}_{\mathrm{o}}$ is the modified Bessel function of the second kind.

To ensure numerical equivalency between Philip's solution and VS2DT, Equation 2 was added to VS2DT and was used in lieu of van Genuchten's (1980) $\mathrm{K}-\psi$ relationship (however, van Genuchten's model was still used to describe the relationship between moisture content and tension).

The VS2DT model grid was $525 \mathrm{~cm}$ wide and $525 \mathrm{~cm}$ long and was discretized into a 42- by 42block matrix, with each block being $12.5 \mathrm{~cm}$ square. The soil hydraulic parameters were taken from Carsel and Parrish (1988) for a sandy loam soil and are listed in Table 7. The boundary conditions consisted of a constant flux of $30,975 \mathrm{~cm} / \mathrm{year}$ from a single node at $\mathrm{x}=0$, $\mathrm{z}=-100 \mathrm{~cm}$ on the model grid, a constant head of zero $\mathrm{cm}$ along the bottom (to represent a water table), and no-flow boundaries everywhere else. The model simulated 80 years of flow and reached steady state in about 72 years. Figure 13 is a contour plot of pressure head showing VS2DT results and those from Philip (1989) using the same hydraulic parameters. When the two plot files were analyzed with by integrating the mass under the pressure head surfaces, the volume of the VS2DT plot was $-2.201 \mathrm{E}+07 \mathrm{~cm}^{3}$, while the Philip curve was $-2.191 \mathrm{E}+07$ $\mathrm{cm}^{3}$. This represents a difference of less than 0.5 percent and was a very good match.

As an additional check, the heads output from the Philip solution were used as initial conditions for a restart of VS2DT. The steady-state head-change criteria was lowered from $0.1 \mathrm{~cm}$ to 0.01 


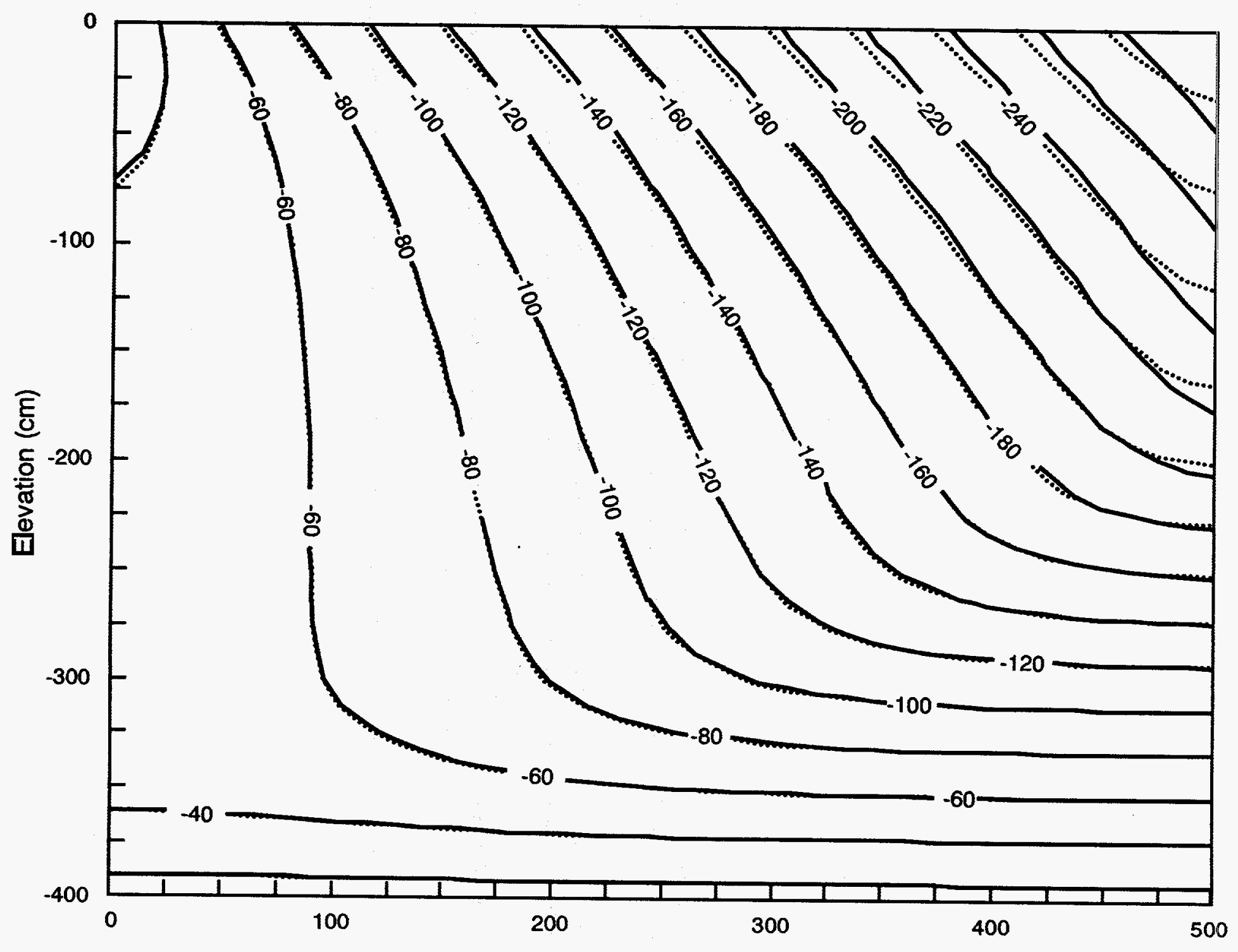

Horizontal Distance $(\mathrm{cm})$

Figure 13

Contour Plots of Unsaturated Pressure Head (cm) As Predicted by VS2DT and Philip (1989) 


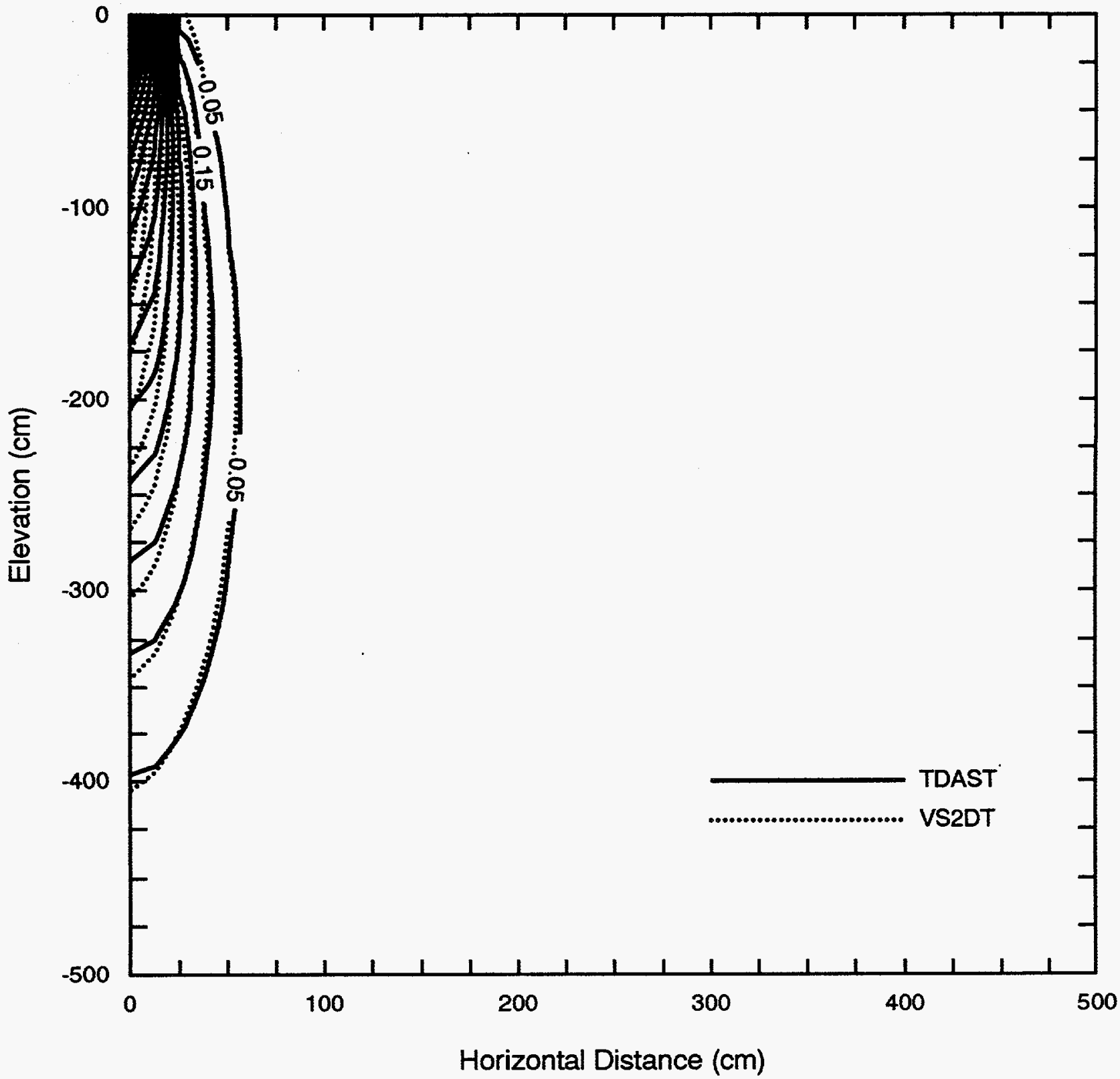

Figure 14

Contour Plots of Solute Concentration (mg/L)

As Predicted by VS2DT and TDAST 
Table 7

Hydraulic Parameters Used in VS2DT Verification

\begin{tabular}{|c|c|}
\hline Parameter & Value \\
\hline \hline Hydraulic Conductivity & $38,719 \mathrm{~cm} /$ year \\
\hline Storage Coefficient & $1 \mathrm{E}-6$ \\
\hline Saturated Moisture Content & 0.41 \\
\hline Residual Moisture Content & 0.06 \\
\hline Van Genuchten's $a$ & $0.08 \mathrm{~cm}^{-1}$ \\
\hline Van Genuchten's $\beta$ & 1.89 \\
\hline Gardner's $\alpha$ & 0.05 \\
\hline
\end{tabular}

cm on the assumption that VS2DT would converge relatively quickly and would predict a solution even closer to Philip's. However, VS2DT converged to the same answer as previously, and the change in mass was identical. This was probably due to the fact that the VS2DT model assumed a no-flow boundary on the right side of the domain. Conversely, the Philip solution appears to allow some flux normal to this boundary; this is evident in Figure 13 along the right side above $200-\mathrm{cm}$ elevation. At any rate, the solutions are still so close to each other that one can feel confident about the verification of VS2DT.

\subsection{Verification Problem 2-Saturated Transport}

This problem simulated two-dimensional solute transport and was solved analytically by Javandel et al. (1984) and dubbed "TDAST." For a two-dimensional steady-state uniform flow field with a constant source at $\mathrm{x}=0, \mathrm{y}=0$, TDAST determines the concentration of a solute by the following equation:

$$
\begin{gathered}
C(x, y, t)=\frac{C_{o} x}{4\left(\pi D_{L}\right)^{1 / 2}} \exp \left[\frac{v x}{2 D_{L}}-\alpha t\right] \\
\cdot \int_{0}^{t / R} \exp \left[-\left[\lambda R-\alpha R+\frac{v^{2}}{4 D_{L}}\right] \tau-\frac{x^{2}}{4 D_{L} \tau}\right] \tau^{-3 / 2} \\
\cdot\left[\operatorname{erf}\left[\frac{a-y}{2\left(D_{T} \tau\right)^{1 / 2}}\right]+\operatorname{erf}\left[\frac{a+y}{2\left(D_{T} \tau\right)^{1 / 2}}\right]\right] d \tau
\end{gathered}
$$


where $C(x, y, t)$ is the concentration at horizontal coordinate locations $(x, y)$ and time $t, C_{0}$ is the initial solute concentration, $\mathrm{v}$ is the pore velocity, $\lambda$ is the radioactive decay constant, $\mathrm{R}$ is the retardation coefficient, $a$ is the half-length of the source, and $\tau$ is $t / R . D_{L}$ and $D_{T}$ are the longitudinal and transverse dispersion coefficients and are computed as $D_{L}=\alpha_{L} V+D^{*}$ and $\mathrm{D}_{\mathrm{T}}=\alpha_{\mathrm{T}} \mathrm{V}+\mathrm{D}^{*}$, where $\alpha$ is the dispersivity, $\mathrm{V}$ is the pore velocity, and $\mathrm{D}^{*}$ is the molecular diffusion.

The VS2DT model grid and hydraulic parameters were the same as described for verification problem $1\left(\Delta \mathrm{X}=\Delta \mathrm{Z}=12.5 \mathrm{~cm}\right.$ with $\left.\mathrm{x}_{\max }=\mathrm{z}_{\max }=525 \mathrm{~cm}\right)$, but the boundary conditions were different. The source (with an initial solute concentration of $1.0 \mathrm{mg} / \mathrm{L}$ ) was still in the upper-left node, but a unit gradient was applied from top to bottom across the model domain by specifying a top and bottom pressure head $\psi=0$. The left and right boundaries were still no-flow, and the simulation time was to one day. The longitudinal and transverse dispersivities were $30 \mathrm{~cm}$ and $3 \mathrm{~cm}$, respectively. Molecular diffusion was $1.0 \mathrm{E}-06 \mathrm{~cm}^{2} /$ year, and retardation and radioactive decay were assumed to be zero. TDAST requires input in the form of dispersion coefficients and an average pore velocity. The pore velocity (assuming an effective moisture content of 0.41) was $94,436 \mathrm{~cm} /$ year, resulting in the longitudinal and transverse dispersion coefficients of $2.83 \mathrm{E}+06 \mathrm{~cm}^{2} /$ year and $2.83 \mathrm{E}+05 \mathrm{~cm}^{2} /$ year, respectively.

Figure 14 shows contour plots of solute concentration after one day of simulation for both TDAST and VS2DT. As with problem 1, the plots were numerically integrated; the volume of the TDAST plot was $3714.9 \mathrm{~cm}^{2} \mathrm{mg} / \mathrm{L}$, while the volume of the VS2DT plot was 3587.7 $\mathrm{cm}^{2} \mathrm{mg} / \mathrm{L}$. The difference between the two simulations was about 1.7 percent and within acceptable limits.

\subsection{Summary and Conclusions}

The variably saturated flow and transport code VS2DT was benchmarked against several other codes with similar capabilities. The benchmark comparison showed the VS2DT code to exhibit equivalent to superior accuracy and performance to the other codes, and VS2DT has the added advantages of being public domain and allowing a free-formatted input structure. VS2DT furthermore was tested on two additional verification problems to check the code's accuracy on two-dimensional flow and transport (the code's original documentation verifies the code for only one-dimensional problems). The verification results indicate that VS2DT can accurately solve the Richards equation and the convection-dispersion equation in two dimensions. 


\subsection{References}

Appel, C. A., 1976, "A Note on Computing Finite Difference Interblock Transmissivities," Water Resources Research, Vol. 12., No. 3.

Batu, V, and W.R. Gardner, 1978, Steady-state convection in two dimensions with non-uniform infiltration, Soil Sci. Soc. Am. J., 42, pp. 18-22.

Carsel, R. F. and R. S. Parrish. 1988. Developing joint probability distributions of soil water retention characteristics, Water Resources Research, Vol. 24, No. 5, pp. 755-769.

Celia, M. A., E. T. Bouloutas, and R. L. Zarba, 1990, "A General Mass-Conservative Solution for the Unsaturated Flow Equation," Water Resources Research, Vol. 26, No. 7.

Cooley, R. L., 1983, "Some New Procedures for Numerical Solution of Variably Saturated Flow Problems," Water Resources Research, Vol. 19.

Haverkamp, R., and M. Vauclin, 1979, "A Note on Estimating Finite Difference Interblock Hydraulic Conductivity Values for Transient Unsaturated Flow Problems, "Water Resources Research, Vol. 15.

Healy, R. W., 1990, "Simulation of Solute Transport in Variably Saturated Porous Media with Supplemental Information on Modifications to the U.S. Geological Survey's Computer Program VS2DT," Water-Resources Investigations Report 90-4025, U.S. Geological Survey, Denver, Colorado.

Hills, R. G., I. Porro, D. B. Hudson, and P. J. Wierenga, 1989, "Modeling One-Dimensional Infiltration Into Very Dry Soils, 1. Model Development and Evaluation," Water Resources Research, Vol. 25, No. 6.

Hindmarsh, A. C., 1983, "ODEPACK, A Systemized Collection of ODE Solvers," in Scientific Computing, R. S. Steplemen (ed.), North-Holland Publishers, Amsterdam.

Huyakorn, P. S., J. B. Kool, and J. B. Robertson, 1989, "Documentation and User's Guide: VAM2D-Variably Saturated Analysis Model in Two Dimensions, "NUREG/CR-5352, HGL/8901, HydroGeoLogic, Inc., Herndon, Virginia.

Javandel, I., C. Doughty, and C. Tsang. 1984. Groundwater transport: handbook of mathematical models, Water Resources Monograph Series 10, American Geophysical Union, Washington, D.C.

Kool, J. B., and J. C. Parker, 1987, "Development and Evaluation of Closed-Form Expressions for Hysteretic Soil Hydraulic Properties," Water Resources Research, Vol. 23, No. 1. 
Kozak, M. W., M. S. Y. Chu, P. A. Mattingly, J. D. Johnson, and J. T. McCord, "Background Information for the Development of a Low-Level Waste Performance Assessment Methodology: Implementation of Computer Codes," NUREG/CR-5453, SAND89-2505, Vol. 5, Sandia National Laboratories, Albuquerque, New Mexico.

Kung, S. K-J., S-H. Ju, and M. Milner, 1991, "Funnel Flow in a Layered Vadose Zone: Laboratory Observation and Finite-Element Modeling," in Proceedings of the Workshop on Characterization of Transport Phenomena in the Vadose Zone, University of Arizona, Tucson, Arizona.

Lappala, E. G., R. W. Healy, and E. P. Weeks, 1987, "Documentation of Computer Program VS2DT to Solve the Equations of Fluid Flow in Variably Saturated Porous Media," WaterResources Investigations Report 83-4099, U.S. Geological Survey, Denver, Colorado.

Magnuson, S. O., R. G. Baca, and A. J. Sondrup, 1990, "Independent Verification and Benchmark Testing of the PORFLO-3 Computer Code, Version 1.0," EGG-BG-9175, Idaho National Engineering Laboratory, Idaho Falls, Idaho.

McCord, J. T., D. B. Stephens, and J. L. Wilson, 1991, "Hysteresis and State-Dependent Anisotropy in Modeling Unsaturated Hillslope Hydrologic Processes," Water Resources Research, Vol. 27, No. 7.

McCord, J. T., 1991, Application of Second-Type Boundaries in Unsaturated Flow Modeling," Water Resources Research, Vol. 27, No. 12.

Milly, P.C.D., 1985, A mass conservative procedure for time-stepping in models of unsaturated flow, Advances in Water Resources, 22, pp. 1790-1808.

Phillip, J.R., 1989, Multidimensional steady Infiltration to a water table, Water Resources Research, Vol. 25, No. 1, pp. 109-116.

Smyth, J. D., E. Bresler, G. W. Gee, and C. T. Kincaid, 1990, "Development of an Infiltration Evaluation Methodology for Low-Level Waste Shallow Land Burial Sites, "NUREG/CR-5523, PNL-7356, Pacific Northwest Laboratory, Richland, Washington.

Updegraff, C. D., C. E. Lee, and D. P. Gallegos, 1991, "DCM3D: A Dual-Continuum, ThreeDimensional, Ground-Water Flow Code for Unsaturated, Fractured, Porous Media," NUREG/CR-5536, SAND90-7015, Sandia National Laboratories, Albuquerque, New Mexico.

Yeh, T-C. J., R. Srivastava, A. Guzman, and T. Harter, 1993, "A Numerical Model for Water Flow and Chemical Transport in Variably Saturated Porous Media," Groundwater, Vol. 31, No. 4. 
Yeh, T-C. J., and R. Srivastava, 1990, "VSAFT2: Variably Saturated Flow and Transport in 2-Dimensions, A Finite Element Simulation," Technical Report No. HWR 90-010, University of Arizona, Tucson, Arizona. 


\section{DISTRIBUTION:}

6 Michael T. Goodrich

IT Corporation

5301 Central Avenue NE, Suite 700

Albuquerque, NM 87108-1513

2 Dr. Pete Weirenga

Soil and Water Science Department

University of Arizona

429 Shantz, Bldg. \#38

Tucson, AZ 85721

1 U.S. Department of Agriculture

Attn: David C. Goodrich, Ph.D.

2000 E. Allen Road

Tucson, AZ 85719

2 Glendon W. Gee

Battelle Pacific Northwest Labs

Geo. Research \& Eng. Dept.

Battelle Boulevard, MS K6-77

Richland, WA 99352

$1 \quad$ Mark Reeves

INTERA, Inc.

101 Convention Center Drive

Las Vegas, NV 89109

1 Dave Petersen

INTERA, Inc.

1650 University Blvd NE, Suite 300

Albuquerque, NM 87102-1732

1 Swen O. Magnusen

EG\&G/INEL

765 Lindsey Blvd.

Idaho Falls, ID 83415

3 Richard W. Healy

U.S. Geological Survey

Water Resources Division

Box 25046, MS 413, Bldg. 53

Denver Federal Center

Lakewood, CO 80225-0046
2 William N. Herkelrath, Ph.D. U.S.G.S., Water Resources Div.

Western Region 345 Middlefield Rd., 'MS 496

Menlo Park, CA 94025

1 Richard G. Hills

Mechanical Engineering

New Mexico State University

Box 30001, Dept. 3450

Las Cruces, NM 88003-0001

3 Daniel B. Stephens

Daniel B. Stephens \& Associates 6020 Academy Road, NE

Albuquerque, NM 87109

1 Kenneth C. Black

Environmental Consulting

Engineers, Inc.

P.O. Box 22668

Knoxville, TN 37933

1 Harriet Rector

ARS - Great Plain Sys. Research

P.O. Box E

Fort Collins, CO 80522

1 John Kramer

Vadose Monitoring Lab

Institute for Crustal Studies

UCSB

Santa Barbara, CA 93106-1100

1 Jim Mercer

GeoTrans, Inc.

46050 Manekin Plaza, Suite 100

Sterling, VA 22170

2 M. Shaheed Hossain, Dr.-Ing.

International Atomic Energy Agency

Waste Management Section

Wagramerstrasse 5, P.O. Box 100

A-1400 Vienna

AUSTRIA 
4 MS-0184 U.S. Dept. of Energy

Attn: John Gould

P.O. Box 5400

Albuquerque, NM 87185

$\begin{array}{lll}1 & \text { MS-0727 } & \text { Galloway, Bob, 6622 } \\ 1 & \text { MS-0727 } & \text { Langfkopf, Brenda, 6622 } \\ 10 & \text { MS-0727 } & \text { McCord, Jim, 6622 } \\ 1 & \text { MS-0827 } & \text { Martinez, Mario, 1511 } \\ 1 & \text { MS-0835 } & \text { Eaton, Roger, 1513 } \\ 1 & \text { MS-1309 } & \text { Environmental Operations Records Center, 7500 } \\ 1 & \text { MS-1324 } & \text { Glass, Bob, 6115 } \\ 1 & \text { MS-1324 } & \text { Holt, Bob, 6115 } \\ 1 & \text { MS-1324 } & \text { Webb, Steve, 6115 } \\ 1 & \text { MS-1345 } & \text { Kozak, Matt, 6331 } \\ 1 & \text { MS-1345 } & \text { Conrad, Steve, 6331 } \\ 1 & \text { MS-1347 } & \text { Cox, Warren, 7581 } \\ 1 & \text { MS-1347 } & \text { Nimick, Fran, 7582 } \\ 1 & \text { MS-1347 } & \text { Roybal, Tony, 7582 } \\ 1 & \text { MS-1347 } & \text { Miller, David, 7582 } \\ 1 & \text { MS-1347 } & \text { Conway, Rarilee, 7582 } \\ 1 & \text { MS-1347 } & \text { Aas, Chris, 7582 } \\ 1 & \text { MS-1347 } & \text { Dawson, Lon, 7582 } \\ 1 & \text { MS-1348 } & \text { Knowlton, Bob, 7583 } \\ 1 & \text { MS-1348 } & \text { Fate, Dick, 7585 } \\ 1 & \text { MS-1348 } & \text { Ardito, Cindy, 7585 } \\ 1 & \text { MS-1348 } & \text { Peace, Jerry, 7585 } \\ 1 & \text { MS-1348 } & \text { Byrd, Caroline, 7585 } \\ 1 & \text { MS-1348 } & \text { Lojek, Carole, 7585 } \\ 1 & \text { MS-1348 } & \text { Laursen, Otto, 7585 } \\ 1 & \text { MS-1350 } & \text { Stermer, Dorothy, 7584 } \\ 1 & \text { MS-1350 } & \text { Collins, Sue, 7584 } \\ 1 & \text { MS-1350 } & \text { Burck, Peter, 7584 } \\ 1 & \text { MS-9018 } & \text { Central Technical Files, 8523-2 } \\ 5 & \text { MS-0899 } & \text { Technical Library, 13414 } \\ 1 & \text { MS-0619 } & \text { Technical Publications, 12613 } \\ 2 & \text { MS-0100 } & \text { Document Processing for DOE/OSTI, 7613-2 }\end{array}$ 